\title{
A model relating transpiration for Japanese cedar and cypress plantations with stand structure
}

\section{AUTHOR(S):}

Komatsu, Hikaru; Shinohara, Yoshinori; Kumagai, Tomo'omi; Kume, Tomonori; Tsuruta, Kenji; Xiang, Yang; Ichihashi, Ryuji; ... Ogura, Akira; Saito, Takami; Otsuki, Kyoichi

\section{CITATION:}

Komatsu, Hikaru ...[et al]. A model relating transpiration for Japanese cedar and cypress plantations with stand structure. Forest Ecology and Management 2014, 334: 301-312

\section{ISSUE DATE:}

2014-12-15

\section{URL:}

http://hdl.handle.net/2433/191207

\section{RIGHT:}

(C) 2014 Elsevier B.V.; This is not the published version. Please cite only the published version.; この論文は出版社版でありません。引用の際に は出版社版をご確認ご利用ください。 
1

2 A model relating transpiration for Japanese cedar and cypress plantations with stand

3 structure

4

5 The name and the affiliation of the authors

6 Hikaru Komatsu ${ }^{1,2}$ *, Yoshinori Shinohara ${ }^{3}$, Tomo’omi Kumagai ${ }^{4}$, Tomonori Kume ${ }^{5}$,

7 Kenji Tsuruta ${ }^{2}$, Yang Xiang ${ }^{6}$, Ryuji Ichihashi ${ }^{6}$, Makiko Tateishi $^{6}$, Takanori Shimizu ${ }^{7}$,

8 Yoshiyuki Miyazawa ${ }^{8}$, Mari Nogata ${ }^{6}$, Sophie Laplace ${ }^{5}$, Tseng Han $^{5}$, Chen-Wei Chiu ${ }^{6}$,

$9 \quad$ Akira Ogura $^{9}$, Takami Saito ${ }^{4}$, Kyoichi Otsuki ${ }^{6}$

10

$11{ }^{1}$ The Hakubi Center for Advanced Research, Kyoto University, Kyoto 606-8302, Japan

$12{ }^{2}$ Graduate School of Agriculture, Kyoto University, Kyoto 606-8502, Japan

$13 \quad{ }^{3}$ Faculty of Agriculture, Kyushu University, Fukuoka 812-8581, Japan

$14{ }^{4}$ Hydrospheric Atmospheric Research Center, Nagoya University, Chikusa-ku, Nagoya 464-8601, Japan

16

${ }^{5}$ School of Forestry and Resource Conservation, National Taiwan University, Taipei 106,

17 Taiwan

$18{ }^{6}$ Kasuya Research Forest, Kyushu University, Fukuoka 811-2415, Japan

19

${ }^{7}$ Forestry and Forest Products Research Institute, Matsunosato, Tsukuba, Ibaraki 3058687, Japan 
$21 \quad{ }^{8}$ Research Institute for East Asia Environments, Kyushu University, Motooka, Fukuoka

22 811-0395, Japan

$23 \quad{ }^{9}$ Ishikawa-ken Forest Experimental Station, Ishikawa 920-2114, Japan

$24 *$ Corresponding author

25

26 Full address, E-mail, telephone, and fax numbers:

27 Hikaru Komatsu, The Hakubi Center for Advanced Research, Kyoto University, Kyoto

28 606-8302, Japan

29

Tel/Fax: +81-75-753-5100/5310

30 E-mail: kmthkr@gmail.com

31 
32 Abstract

33 Previous studies have revealed that changes in forest structure due to management (e.g., 34 thinning, aging, and clearcutting) could affect the forest water balance. However, there 35 are unexplained variability in changes in the annual water balance with changing structure among different sites. This is the case even when analyzing data for specific species/regions. For a more advanced and process-based understanding of changes in the water balance with changing forest structure, we examined transpiration $(E)$ observed using the sap-flux method for 14 Japanese cedar and cypress plantations with various structure (e.g., stem density and diameter) in Japan and surrounding areas and developed a model relating $E$ with structural parameters. We expressed $E$ using the simplified Penman-Monteith equation and modeled canopy conductance $\left(G_{c}\right)$ as a product of reference $G_{c}\left(G_{c r e f}\right)$ when vapor pressure deficit is $1.0 \mathrm{kPa}$ and functions expressing the responses of $G_{c}$ to meteorological factors. We determined $G_{c r e f}$ and parameters of the functions for the sites separately. $E$ observed for the 14 sites was not reproduced well by the model when using mean values of $G_{c r e f}$ and the parameters among the sites. However,

$47 \quad E$ observed for the sites was reproduced well when using $G_{c r e f}$ determined for each site and mean values of the parameters of the functions among the sites, similar to the case

49 when using $G_{c r e f}$ and the parameters of the functions determined for each site. These

50 results suggest that considering variations in $G_{c r e f}$ among the sites was important to

51 reproduce variations in $E$, but considering variations in the parameters of the functions 
52 was not. Our analysis revealed that $G_{c r e f}$ linearly related with the sapwood area on a stand

53 scale $(A)$ and that $A$ linearly related with stem density $(N)$ and powers of the mean stem

54 diameter $\left(d_{m}\right)$. Thus, we proposed a model relating $E$ with $A$ (or $N$ and $d_{m}$ ), where $G_{c r e f}$

55 was calculated from $A$ (or $N$ and $d_{m}$ ) and the parameters of the functions were assumed to

56 be the mean values among the sites. This model estimates changes in $E$ with changing

57 structure from commonly available data ( $N$ and $d_{m}$ ), and therefore helps improve our

58 understanding of the underlying processes of the changes in the water balance for

$59 \quad$ Japanese cedar and cypress plantations.

60

61 Key words: canopy conductance; forest structure; model; sapwood area; simplified 
1. Introduction

Changes in forest structure due to management (e.g., planting, growth, thinning, aging, and clearcutting) can affect the forest water balance. Numerous studies (Scott and Lesch, 1997; Cornish and Vertessy, 2001) have examined changes in the annual water balance with changing forest structure on the basis of catchment water balance data. Summarizing data derived from such studies and analyzing them using linear regression, researchers have identified several important parameters (e.g., the ratio of the cutting area to the total catchment area, annual rainfall, and leaf phenology) determining changes in annual runoff with changing structure (Bosch and Hewlett, 1982; Brown et al., 2005; Komatsu et al., 2011). However, there remains unexplained variability in changes in the annual water balance (Bosch and Hewlett, 1982; Brown et al., 2005). This is the case even for data for a single species within a specific region, although the variability is less pronounced (Adams and Fowler, 2006; Komatsu et al., 2011). This suggests the limitation of analyzing catchment water balance data simply using linear regression without considering underlying processes (e.g., canopy transpiration and interception evaporation). For a more advanced understanding of changes in the annual water balance with changing structure, examining relationships of canopy transpiration and interception for given species with various structure (e.g., stem density and diameter) would be useful (Komatsu et al., 2007d). Variations in stem density and diameter relate with the sapwood area on a stand scale and leaf area index, which could in turn relate with canopy 
transpiration (Granier et al., 2000a; Ewers et al., 2011). Focusing on specific species would be useful in reducing factors to be considered, because there are factors (e.g., the clumpling factor and stem conductivity) that could differ among different species and affect canopy transpiration (Baldocchi and Meyers, 1998; Zwieniecki and Holbrook, 1998; Bréda, 2003).

Japanese cedar (Cryptomeria japonica) and cypress (Chamaeryparis obtusa) are major plantation species in Japan and surrounding areas such as China and Taiwan (Japan Forestry Agency, 2014). Examining the water balance of these plantations is highly important from a practical viewpoint. Forest management (e.g., thinning) has been performed to increase water resources in Japan, although its effectiveness has not been assessed sufficiently (Komatsu et al., 2010). Summarizing data for interception evaporation of Japanese cedar and cypress plantations (Hattori et al., 1982; Tanaka et al., 2005), Komatsu et al. (2007a) found a relationship between stem density and interception evaporation and then developed a model relating interception evaporation with stem density. However, there have been few studies examining the relationship between forest structure and canopy transpiration $(E)$ for Japanese cedar and cypress plantations. To assess changes in the water balance of Japanese cedar and cypress plantations with changing forest structure, we developed a model relating $E$ for Japanese cedar and cypress plantations with meteorological and structural variables. The model formulates $E$ using the simplified Penman-Monteith equation (McNaughton and Black, 1973; Jarvis 
104

105

and McNaughton, 1986). Canopy conductance $\left(G_{c}\right)$ in the equation was written as a series of functions expressing responses of $G_{c}$ to meteorological factors (Jarvis, 1976; Lohammer et al., 1980). This study comprises three steps. First, we calculated $G_{c}$ using $E$ data derived employing the sap-flux method for 14 sites and the inverted form of the simplified Penman-Monteith equation to determine parameters of the model for the sites separately. Second, we assessed the importance of each parameter in determining $E$ on the basis of sensitivity analysis. Third, we examined the relationship of the important parameters with structural parameters. Here, we tried to relate the structural parameters with commonly available data such as stem density and diameter for wide use of the model.

Models estimating $E$ are roughly classified into two groups. One uses many empirical parameters for modeling stomatal/canopy conductance to avoid considering internal hydraulics and keep the model structure simple (Granier et al., 2000a; Komatsu, 2004), while the other considers internal hydraulics (Domec et al., 2012; McDowell et al., 2013). Our model belongs to the former group. Most models of the former group focus on reproducing E for a specific site (Cienciala et al., 1994a,b; Granier and Bréda, 1996). Several models (Granier et al., 2000a; Komatsu, 2004) are applicable to various sites, similar to our model. Our model differs from these models in that our model focuses on two species, which suggests higher predictability of the model when applied to the species. Furthermore, our model differs from the models in that our model would be tested against 
$124 E$ data recorded not only during growing seasons but during winter, suggesting higher

125 reliability of the model to predict $E$ on a long time scale (e.g., one year).

126

2. Theory

128

The model, using the simplified Penman-Monteith equation (McNaughton and

Black, 1973; Jarvis and McNaughton, 1986), expresses $E$ as

130

$$
E=\frac{\rho C_{p} G_{c} D}{\gamma \lambda}
$$

where $\rho$ is the air density, $C_{p}$ is the specific heat of air, $G_{c}$ is canopy conductance, $D$ is the vapor pressure deficit, $\gamma$ is the psychrometric constant, and $\lambda$ is the latent heat of water vaporization. This equation is derived from the Penman-Monteith equation under the assumption of complete coupling between the canopy and atmosphere.

( $G_{c r e f}$, Oren et al., 1999) and functions expressing responses of $G_{c}$ to meteorological factors (Jarvis, 1976; Lohammer et al., 1980):

138

$$
G_{c}=G_{\text {cref }} \cdot f(D) \cdot g(R) \cdot h(T)
$$
where $f(D), g(R)$, and $h(T)$ are functions expressing the responses of $G_{c}$ to mean daytime $D$, solar radiation $(R)$, and air temperature (T), respectively. $f(D), g(R)$, and $h(T)$ are respectively modeled as (Oren et al., 1999; Granier et al., 2000b)

$$
f(D)=1.00-\beta \cdot \ln (D),
$$

$$
g(R)=\min \left\{\left(\frac{R}{600}\right)^{\delta}, 1.00\right\},
$$




$$
h(T)=\left\{\begin{array}{lc}
1.00 & (T \geq \epsilon) \\
\frac{T-\zeta}{\epsilon-\zeta} & (\zeta<T<\epsilon), \\
0.00 & (T \leq \zeta)
\end{array}\right.
$$

145 where $\beta, \delta, \varepsilon$, and $\zeta$ are parameters. The model does not consider the effect of the soil water deficit on $G_{c}$. Most previous studies, making continuous measurements of $E$ (or its substitutes) for forests in Japan including Japanese cedar and cypress plantations (Komatsu et al., 2006; Kosugi et al., 2007; Kumagai et al., 2007), did not report a clear reduction in $G_{c}$ or $E$ with a soil water deficit, although there were a few exceptions (Tanaka et al., 2002; Komatsu et al., 2007c). We hypothesized that considering the variation in $G_{c r e f}$ among sites would be important but considering variations in $\beta, \delta, \varepsilon$, and $\zeta$ among sites would not be in reproducing $E$ for the sites. Our hypothesis was based on results of previous studies. $G_{c r e f}$ linearly relates with $E$ in the simplified Penman-Monteith equation. $G_{c r e f}$ values reported previously (Granier et al., 2000a; Komatsu et al., 2012, 2013) often differ greatly among different forest sites comprising the same species, implying that considering the variation in $G_{c r e f}$ among the sites is important in estimating $E$. Oren et al. (1999) and succeeding studies (Addington et al., 2004; Ewers et al., 2008) noted a fairly conservative $\beta$ among different sites. Thus, assuming $\beta$ as constant among sites might not introduce large errors in $E$ estimates. Komatsu et al. (2006) analyzed sap flux data on an hourly time scale for a Japanese cedar plantation and pointed out that the control of $G_{c}$ by $R$ was important only 
162 early in the morning and late afternoon, when $E$ is small. This implies that assuming $\delta$ as 163 constant among sites would not introduce large errors in estimating $E$ on a daily time 164 scale. $\varepsilon$ and $\zeta$ affect $E$ during winter, which accounts for a small portion of annual $E$ for 165 Japanese cedar and cypress plantations (Suzuki, 1980; Kumagai et al., 2014). Thus, 166 assuming $\varepsilon$ and $\zeta$ as constant among sites might not introduce large errors in estimating $167 E$ on a longer time scale, such as one year. We further hypothesized that $G_{c r e f}$ would relate with the sapwood area on a stand scale (A) for the following reasons. Kumagai et al. (2007) examined $E$ for two cedar forest sites located nearby but having different $A$. The relative difference in $E$ between the sites was comparable to that in $A$. Komatsu et al. (2013) compared $E$ values for a cedar forest during two successive growing seasons just before and after thinning. The ratio of $E$ after thinning to that before thinning approximated the ratio of $A$ after thinning to that before thinning. The results of Kumagai et al. (2007) and Komatsu et al. (2013) suggest a correlation between $A$ and $G_{c r e f}$. Previous studies (Macfarlane et al., 2010; Ewers et al., 2011) reported relationships between $A$ and $E$ for forests comprising other species. These results also suggest that our hypothesis is reasonable. The relationship between $A$ and $G_{c r e f}$ would allow the estimation of $G_{c r e f}$ with the input of $A$, and then the estimation of $E$ by assuming typical values of $\beta, \delta$, $\varepsilon$, and $\zeta$ and using the simplified Penman-Monteith equation. 
182

184

3. Data used

We used $E$ data recorded for nine Japanese cedar and five Japanese cypress plantations (Table 1). Twelve of the 14 sites were located in western Japan, but the IK and XT sites were located in eastern Japan and in Taiwan, respectively. Structural parameters differed among the sites. Stem density $(N)$ ranged between 600 and 1575 stems ha ${ }^{-1}$ for cedar and between 350 and 2100 stems ha $^{-1}$ for cypress. The mean diameter at breast height $\left(d_{m}\right)$ ranged between 13.5 and $48.4 \mathrm{~cm}$. The leaf area index $(L)$, estimated using optical methods (see the footnote \#2 of Table 1), ranged between 0.8 and $5.9 \mathrm{~m}^{2} \mathrm{~m}^{-2}$ for cedar and between 0.8 and $4.8 \mathrm{~m}^{2} \mathrm{~m}^{-2}$ for cypress. Note that $L$ for Japanese cedar and cypress forests estimated using optical methods is generally lower than that estimated using destructive leaf sampling and/or allometry equations (Hasegawa et al., 2013; Tsuruta et al., 2014). The sapwood area at a stand scale (A) ranged between 14.1 and 46.0 $\mathrm{m}^{2} \mathrm{ha}^{-1}$ for cedar and between 8.8 and $20.4 \mathrm{~m}^{2} \mathrm{~m}^{-2}$ for cypress. $A$ was determined by measurements of sapwood thickness using core sampling and assuming the stem crosssection was circular. A complete description of the measurements was provided by Kumagai et al. (2007) and Kume et al. (2010).

$E$ values for all sites were measured employing the sap-flux method and Granier sensors (Granier, 1987). A detailed description of the measurements is available in the papers cited in Table 1. Employing the method, $E$ was estimated as (Kumagai et al., 2007; Kume et al., 2010) 


$$
E=\frac{\sum_{i=1}^{n} F_{i} \cdot a_{i}}{S},
$$

203 where $F$ is the sap flux for an individual tree averaged over its sapwood area, $a$ is the tree

204 sapwood area, $n$ is the number of trees in the plot, and $S$ is the ground area. For a tree

205 whose sapwood thickness was much greater than the sensor length (i.e., $2.0 \mathrm{~cm}$ ), two or 206 three sensors were installed radially to cover the sapwood area (Kumagai et al., 2007). F 207 was calculated as the weighted average of sap flux for the sensors. Azimuthal variations 208 of sap flux were also considered for some sites (Shinohara et al., 2013a).

\section{Methods of analysis}

\subsection{Determination of parameters}

We calculated canopy conductance $\left(G_{c}\right)$ from $E$ estimated using the sap-flux method and meteorological factors for each site using the inverted form of the simplified

214 Penman-Monteith equation:

$$
G_{C}=\frac{\gamma \lambda E}{\rho C_{p} D} .
$$

$216 G_{c}$ was calculated as a daily average conductance using mean daytime $T$ and $D$, and $E$ 217 summed over $24 \mathrm{hr}$ but divided by daylight hours (Phillips and Oren, 1998; Kumagai et 218 al., 2008). Sap-flux sensors observe water movement through the trunk during nighttime, 219 which may represent recharge of water into upper sections of the tree trunk and branches or transpiration during nighttime. Dividing $E$ by daylight hours assumes that sap flux observed during nighttime represents recharge of water. Recent studies (Dawson et al., 
2007; Fisher et al., 2007; Oishi et al., 2008) have reported that transpiration during

223 nighttime accounts for a considerable portion of daily transpiration. However,

224 transpiration during nighttime would be very low in Japan possibly because of low $D$

225 during nighttime, as shown by measurements of transpiration using the leaf-chamber

226 method (Kosugi et al., 1995, 1997; Tanaka et al., 2002). The “daytime” here was assumed

227 as the period between 6 a.m. and 6 p.m. throughout the year for simplicity, i.e., the

228 daylight hours were assumed as 12. These assumptions were also made in previous

229 studies (Kumagai et al., 2008; Komatsu et al., 2012). We confirmed that these

230 assumptions did not alter our conclusions. $D$ for the period between 6 a.m. and 6 p.m.

231 differed from $D$ for the period between sunrise and sunset by no more than $8 \%$ for our

232 sites. Our preliminary analysis revealed that $G_{c}$ calculated using $D$ for the period between

2336 a.m. and 6 p.m. could differ from those calculated using $D$ for the period between sunset

234 and sunrise by no more than $10 \%$, which was not large enough to alter our conclusions.

We determined $G_{c r e f}, \beta, \delta, \varepsilon$, and $\zeta$ for the sites where year-round $E$ data were available.

Note that analysis for the XT site did not follow this policy, as detailed later.

The parameters were determined in a manner similar to that employed by

Komatsu et al. (2012, 2013). We first excluded data recorded on rainy days and days with 
242 measurement errors on rainy days (Kumagai et al., 2008; Komatsu et al., 2012). $G_{c}$ could

243 be highly affected by measurement errors in $D$ when $D$ is very low (Ewers and Oren,

244 2000; Komatsu et al., 2007b). We then examined the relationship between $D$ and $G_{c}$ using

245 data recorded on days with high $R\left(>400 \mathrm{~W} \mathrm{~m}^{-2}\right)$ and $T\left(>15^{\circ} \mathrm{C}\right)$. We determined $G_{c r e f}$

246 and $\beta$ by regressing the relationship emloying the least-squares method. After

247 determining $G_{c r e f}$ and $\beta$, we examined the relationship between $R$ and observed $G_{c}$ divided

248 by $G_{c r e f} f(D)$ using data recorded on days with high $T\left(>15^{\circ} \mathrm{C}\right)$ to determine $\delta$. Here, we

249 confirmed that the relationship between soil water content and observed $G_{c}$ divided by

$250 G_{c r e f} f(D) g(R)$ was generally unclear for sites where data for soil water content were

251 available. We finally examined the relationship between $T$ and observed $G_{c}$ divided by

$252 G_{c r e f} f(D) g(R)$ to determine $\varepsilon$ and $\zeta$. Here, we also confirmed that the relationship between

$253 T$ and observed $G_{c}$ divided by $G_{c r e f} f(D) g(R)$ was generally unclear for the sites where $E$

254 data only during the growing season were available.

was located in a mountainous region under a humid subtropical climate. If we had applied the same method as that applied to other sites, we would have only limited data with which to examine the relationship between $D$ and $G_{c}$ because of a large number of rainy days and days with low $R$. The method applied to XT was as follows. We first excluded data recorded on days with daily rainfall more than $5.0 \mathrm{~mm}$ and days with $D$ lower than 
262 days with $R$ no less than $300 \mathrm{~W} \mathrm{~m}^{-2}$. We determined $G_{\text {cref }}$ and $\beta$ by regressing the

263 relationship employing the least-squares method. Here, we confirmed that there was no

264 systematic difference in $G_{c}$ between days without rain and days with rain no more than

$2655.0 \mathrm{~mm}$. After determining $G_{c r e f}$ and $\beta$, we examined the relationship between $R$ and

266 observed $G_{c}$ divided by $G_{c r e f} f(D)$ to determine $\delta$. In the above analysis, we did not exclude

267 data using a criterion about $T$, because the range of $T$ was narrow for XT and a large

268 portion of the data satisfied $T$ being no less than $15{ }^{\circ} \mathrm{C}$. We did not determine the

269 parameters in $h(T)$, because we did not find a clear relationship between $T$ and observed

$270 G_{c}$ divided by $G_{c r e f} f(D) g(R)$ for XT.

4.2. Assessing the importance of parameters

We hypothesized that considering the variation in $G_{c r e f}$ among the sites would be important but considering variations in $\beta, \delta, \varepsilon$, and $\zeta$ among the sites would not be in reproducing $E$ for the 14 sites (detailed in the theory). To verify this hypothesis, we calculated $E$ for days with no rain and $T$ no less than $15^{\circ} \mathrm{C}$ (corresponding to a growing season) for the sites using three different parameterizations: (P1G) the mean values of $G_{c r e f}, \beta$, and $\delta$ among the sites, (P2G) $G_{c r e f}$ determined for each site and the mean values of $\beta$ and $\delta$ among the sites, and (P3G) $G_{c r e f}, \beta$, and $\delta$ determined for each site. To evaluate the reproducibility of $E$ by P1G, P2G, and P3G, we examined the relationships of the mean $E$ for the days calculated using P1G, P2G, and P3G respectively with the mean 
282 observed $E$. If the difference in reproducibility between P1G and P2G was found to be 283 important, considering the variation in $G_{c r e f}$ among the sites would be important in 284 calculating the mean $E$ for a growing season. If the difference in reproducibility between P2G and P3G was found to be unimportant, considering variations in $\beta$ and $\delta$ would not be important. Similarly, we calculated $E$ for days with no rain for sites having data recorded in winter as well as those recorded in a growing season using three different parameterizations: (P1W) the mean values of $G_{c r e f}, \beta, \delta, \varepsilon$, and $\zeta$ among the sites, (P2W) $G_{c r e f}$ determined for each site and the mean values of $\beta, \delta$, $\varepsilon$, and $\zeta$ among the sites, and (P3W) $G_{c r e f}, \beta, \delta$, $\varepsilon$, and $\zeta$ determined for each site. To evaluate the reproducibility of $E$ by P1W, P2W, and P3W, we examined the relationships of the mean $E$ for the days calculated using P1W, P2W, and P3W respectively with the mean observed E. If the difference in reproducibility between P1W and P2W was found to be important, considering the variation in $G_{c r e f}$ would be important in calculating the mean $E$ for a period including a growing season and winter. If the difference in reproducibility between P2W and $\mathrm{P} 3 \mathrm{~W}$ was found to be unimportant, considering variations in $\beta, \delta, \varepsilon$, and $\zeta$ among the sites would not be important. on a longer time scale, because our model was intended to be used to improve our understanding of the forest water balance on a long time scale (see Section 1). For 
assessing the importance of the difference in reproducibility between different parameterizations, we did not examine whether there was a statistically significant difference between errors in $E$ estimates using different parameterizations. What we need to know is not whether there is a statistical difference, but whether the magnitude of the difference is important in a practical context (Bakan, 1966; Thompson, 1996, 1998; Nuzzo, 2014). We thus examined whether errors in estimates of the mean $E$ made using the $G_{c}$ model were less than potential errors in observed $E$. Kumagai et al. (2007) and Kume et al. (2010) examined uncertainty in $E$ estimates made using the sap-flux method for Japanese cedar and cypress plantations. Sampling data for sap flux on a sensor scale repeatedly using the Monte-Carlo technique, Kumagai et al. (2007) and Kume et al.

312 (2010) revealed that the standard variation of $E$ estimates was generally $10 \%$ or more of the mean $E$. When considering that $95 \%$ of data theoretically fall in the range of two standard deviations above and below the mean, potential errors in observed $E$ would be less than $20 \%$ of the value in most cases. If errors in $E$ estimates made using different parameterizations were more than $20 \%$ of observed $E$, we would regard the difference in reproducibility as important. In addition, we examined whether errors in estimates of the mean $E$ made using the $G_{c}$ model were less than those in interception evaporation estimates made using the model developed by Komatsu et al. (2007a) or its revised form developed by Komatsu et al. (submitted), because our $G_{c}$ model was intended to be used with the interception 
evaporation model to assess the water balance for Japanese cedar and cypress plantations

323 (Komatsu et al., submitted). The typical errors in interception evaporation estimates for 324 the period with $T$ no less than $15^{\circ} \mathrm{C}$ and for a year would be 0.22 and $0.20 \mathrm{~mm}^{-1 a y}{ }^{-1}$, respectively (Appendix A).

4.3. Relating important parameters with species and structures

We examined the relationship between $A$ and $G_{c r e f}$ to model $G_{c r e f}$ using $A$. After confirming correlation between the two variables, we regressed the relationship to obtain a linear equation relating $G_{c r e f}$ with $A$. The intercept of the equation was assumed to be zero. The slope of the equation was determined employing the least-squares method. To examine the stability of the correlation and the slope, we calculated $95 \%$ confidence intervals of these variables employing the bootstrapping method (Efron, 1979; Diaconis and Efron, 1983). These intervals were "bias-corrected, accelerated” percentile intervals calculated in the manner described by Efron (1987) and Fox (2008).

As data for $A$ are not usually available for most Japanese cedar and cypress plantations, we tried to relate $A$ with the mean diameter at breast height $\left(d_{m}\right)$ and stem density $(N)$ data in the following way. Tsuruta et al. (2011) summarized data for the sapwood area at a tree scale (a) for 81 cedar trees from six sites and 109 cypress trees from nine sites and examined the relationships between diameter at breast height $(d)$ and $a$ for these species. They did not find clear differences in the relationship among sites. 
342 They regressed the data to develop general equations for the relationships: $a=a_{r e f} \cdot d^{k}$, 343 where $a$ and $d$ were respectively in units of $\mathrm{cm}^{2}$ and $\mathrm{cm}$ and $a_{r e f}$ and $k$ were parameters. $344 a_{\text {ref }}$ was 1.40 and $1.96 \mathrm{~cm}^{2}$ for cedar and cypress, respectively. $k$ was 1.55 and 1.42 for 345 cedar and cypress, respectively. Approximating this equation by the tangential line at $d$ 346 being equal to $d_{m}, A$ was expressed as $A=N \cdot a_{\text {ref }} \cdot d_{m}{ }^{k}$. To examine the validity of this method of estimating $A$ from $N$ and $d_{m}$, we investigated the relationship between $A$ estimated employing this method and observed A. For this validation, we used $A$ data for YB, YA, IS, KL, KU, KS, XT, and IH, and another cypress site of Sun et al. (2014). Data for the other six sites (i.e., IK, IR, OL, OU, SK, and HW) were not used, because $a$ data for the sites were used by Tsuruta et al. (2011) to develop the relationship between $d$ and $a$.

5. Results

\subsection{Determination of parameters}

Figure 1 shows the relationships between $D$ and $G_{c}$, between $R$ and $G_{c}$ divided by $G_{c r e f} f(D)$, and between $T$ and $G_{c}$ divided by $G_{c r e f} f(D) g(R)$. Here, we show data only for OL as an example. Regressing these relationships and relationships for the other sites, parameters for the sites were determined as listed in Table 2. The maximum $G_{\text {cref }}(9.77$ $\mathrm{mm} \mathrm{s}^{-1}$ for IK) among the sites was more than five times the minimum $G_{c r e f}\left(1.76 \mathrm{~mm} \mathrm{~s}^{-}\right.$ 
$362{ }^{1}$ for $\mathrm{IH}$ ). We observed variations in $f(D), g(R)$, and $h(T)$ among sites (Figure 2).

5.2. Assessing the importance of parameters

Figure 3 shows the relationships of the mean $E$ for days with no rain and $T$ no

less than $15{ }^{\circ} \mathrm{C}$ calculated using P1G, P2G, and P3G with observed E. E calculated using the model was not strongly correlated ( $r=0.454)$ with observed $E$ for P1G, but was strongly correlated ( $r=0.993$ and 0.997 , respectively) and fell along the $1: 1$ line for P2G and P3G. Errors for P1G were often greater than potential errors in observed $E$ and interception evaporation estimates, but errors for P2G and P3G were not. Figure 4 shows the relationships of mean $E$ for days with no rain calculated using P1W, P2W, and P3W with observed $E$ for sites having data recorded in winter as well as those recorded in a growing season. $E$ calculated using the model was not strongly correlated ( $r=0.597)$ with observed $E$ for P1W, but was strongly correlated ( $r=0.999$ and $>0.999$, respectively) and fell along the 1:1 line for P2W and P3W. Errors for P1W were often greater than potential errors in observed $E$ and interception evaporation estimates, but errors for P2W and P3W were not. These results suggest that considering the variation in $G_{c r e f}$ among the sites was important for reproducing the mean $E$ on a long time scale, but considering variations in $\beta, \delta$, $\varepsilon$, and $\zeta$ was not. 
382

year-round data were available. Figure 5 shows time series of $E$ calculated using P1W, P2W, and P3W and observed E. Here, we show data only for OU as an example. The slope of the regression line for the relationship between calculated and observed $E$ often fell outside the range between 0.8 and 1.2 for P1W, where the range corresponded to the uncertainty in observed $E$. However, the slope always fell in the range for P2W and P3W (Table 3). The determination coefficients for P1W and P2W were often lower than that for P3W. However, the difference was relatively small. These results suggest that considering the variation in $G_{c r e f}$ among the sites was important for reproducing seasonal and day-to-day variations in $E$, but considering variations in $\beta, \delta$, $\varepsilon$, and $\zeta$ was not.

\subsection{Relating important parameters with species and structures}

$G_{c r e f}$ tended to increase with $A$ (Figure 6). The correlation coefficient (r) was 0.698 and the $95 \%$ confidence interval was $(0.446,0.951)$, when pooling data for cedar and cypress. The correlation between $A$ and $G_{c r e f}$ was stronger than that between $L$ and $G_{c r e f}(r=0.479)$. The regression line was determined as $G_{c r e f}=0.157 A$, where $A$ and $G_{c r e f}$ were in units of $\mathrm{m}^{2} \mathrm{ha}^{-1}$ and $\mathrm{m} \mathrm{s}^{-1}$, respectively. The $95 \%$ confidence interval of the slope was $(0.127,0.195)$. Data for both cedar and cypress were located along the regression line, suggesting no clear difference in $G_{c r e f}$ for a given $A$ between cedar and cypress. Thus, the regression equation could be used to predict $G_{c r e f}$ from $A$ for both cedar and cypress plantations and then to predict E. Figure 7 shows the normal probability plot (Fujii, 2005; 
402 Peck and Devore, 2005) for differences between $G_{c r e f}$ estimated using the regression

403 equation and observed $G_{c r e f}$, where the normal score in the y-axis indicates the difference

404 divided by the standard deviation of the difference for the 14 sites. Data for all sites except

405 SK and IK were approximated by a line, indicating that most of these data followed a

406 normal distribution. However, data for SK and IK were located far from the line,

407 suggesting that observed $G_{c r e f}$ for these sites was higher than expected from the regression

408 equation and a normal distribution of the differences between estimated and observed

$409 G_{\text {cref. }}$

Figure 8 compares $A$ estimated from $N$ and $d_{m}$ and observed $A$. Data were generally located around the 1:1 line. The mean relative error (i.e., the ratio of the difference between estimated and observed $A$ to observed $A$ ) was 26\%. The magnitude of this error is discussed in Section 6.3.

\section{Discussion}

6.1. Roles of $f(D), g(R)$, and $h(T)$

Our model succeeded in reproducing $E$ observed for the 14 sites, suggesting

418 validity of our hypothesis. Our model includes three functions, i.e., $f(D), g(R)$, and $h(T)$.

419 These functions influence on calculated $E$ differently. Omitting $f(D)$ from Eq. (2) (i.e., assuming $f(D)$ being 1.0) causes overestimation of $E$ during May-August (Figure 9a), resulting in a relatively low determination coefficient $\left(R^{2}=0.740\right)$ for the relationship 
422 between calculated and observed $E$. This suggests that considering reduction in $G_{c}$ with 423 increasing $D$ is important in reproducing $E$ when $D$ is high. Omitting $g(R)$ causes overestimation of $E$ during October-January when $R$ is relatively low. Omitting $h(T)$ causes overestimation of $E$ during January-February when $T$ is relatively low. However, the determination coefficients for these cases $\left(R^{2}=0.792\right.$ and 0.798 , respectively) are higher than that for the case of omitting $f(D)$. This suggests that effects of omitting $g(R)$ and $h(T)$ on reproducing $E$ on a daily time scale are less important than that of omitting $f(D)$. $G_{c r e f}$ values for SK and IK were higher than expected from the regression equation (Figure 7). There are technical factors that potentially affect variations in $G_{c r e f}$ among sites. An insufficient number of sensors for sap flux measurements could result in large errors in $E$ estimates. Shinohara et al. (2013a) compared errors in $E$ estimates introduced by ignoring tree-to-tree variations, radial variations, and circumference variations in sap flux for a Japanese cedar plantation. They concluded that tree-to-tree variations in sap flux are the primary factor of errors in $E$ estimates. Previous studies (Kumagai et al., 2005, 2007; Kume et al., 2010; Shinohara et al., 2013b) reported that errors in $E$ estimates for Japanese cedar and cypress were serious when the number of trees in which sensors were installed was low, especially when there were less than 
442 approximately 10 . Note that this threshold number would be species specific, because 443 different threshold numbers were reported for other species (Oren et al., 1998; Mackay et 444 al., 2010). There were approximately 10 in which sensors were installed at each site (10 445 for SK and 9 for IK). Furthermore, $E$ for IK estimated from sap flux data derived for nine 446 trees differed less than 5\% from that estimated from sap flux data derived for all 18 trees 447 according to intensive measurements performed during May 16-18 and June 1-4, 2010 448 for the site. Thus, the numbers of sensors at these sites are not likely a main factor 449 explaining the higher $G_{c r e f}$. The use of the simplified Penman-Monteith equation could also be a factor causing higher $G_{c r e f}$. Aerodynamic conductance, which is assumed as infinite in the simplified Penman-Monteith equation, generally ranges between 70 and $400 \mathrm{~mm} \mathrm{~s}^{-1}$ for coniferous forests including Japanese cedar and cypress plantations (Stewart and Thom, 1973; Yamanoi and Ohtani, 1992; Loustau et al., 1996; Tanaka et al., 1996). When assuming aerodynamic conductance as $70 \mathrm{~mm} \mathrm{~s}^{-1}$ and calculating $G_{c r e f}$ using the original Penman-Monteith equation (see the methods used by Komatsu et al., 2012), $G_{\text {cref }}$ values for SK and IK are determined as 3.53 and $6.22 \mathrm{~mm} \mathrm{~s}^{-1}$, respectively. These $G_{c r e f}$ data are located close to the regression line in Figure 6, implying that the use of the simplified Penman-Monteith equation might be a potential factor explaining the higher $G_{c r e f}$ for the sites. Unfortunately, there have been no data for aerodynamic conductance observed at these sites. However, data for wind speed for IK are available. The relationship between 
$D$ and $G_{c}$ differed only slightly according to wind speed, suggesting that low aerodynamic

463

464 conductance would not be the primary factor causing low $G_{c r e f}$ for IK. Data for wind speed for SK were unavailable.

Besides the factors discussed above, age might be another possible factor explaining high $G_{c r e f}$ for SK, which is younger than the other sites (Table 1). There have been several studies reporting or suggesting changes in sap flux on a stand scale with age for mono-specific forests (Tsuruta et al., 2008; Forrester et al. 2010). We do not have data for other sites of similar age to SK. We thus recommend examining $G_{c r e f}$ for young Japanese cedar and cypress plantations.

\subsection{Errors in $A$ estimates}

We observed a clear correlation between estimated and observed $A$ (Figure 8).

However, the error in $A$ estimates was relatively large. The mean relative error in $A$ estimates (26\%) was comparable to that in $G_{c r e f}$ estimates obtained using the regression equation in Figure 5 (24\%). Thus, it would be better to use observed $A$ to calculate $G_{c r e f}$, if observed $A$ is available.

The error in A estimates would be primarily caused by errors in $a$ estimates using Tsuruta et al.’s (2011) equation, and only secondarily caused by errors due to tangential approximation of the equation (Eq. (8)). The tangential approximation could cause underestimation of $A$, because $a$ values calculated using the tangential line are no more 
482

483

484

485

486

487

488

489

490

491

492

493

494

495

496

497

498

499

500

501

than those calculated using the original equation. In fact, $A$ estimated employing the above method did not always underestimate observed $A$ (Figure 8).

\subsection{Possible applications and implications}

Our model would be useful as a research tool for hydrologists. There have been many studies (Dung et al., 2012; Kubota et al., 2013) examining changes in the annual water balance with changing structure of Japanese cedar and cypress plantations due to forest management. There are large variations in the change in the annual water balance among studies. Our model, accompanied with the interception evaporation model developed by Komatsu et al. (2007a), could be used by hydrologists to calculate changes in $E$ and interception evaporation for catchments and improve our understanding of underlying processes of the variations. Our model and the interception model are also useful in estimating spatial variations in $E$ and interception evaporation on a landscape scale, when these models are used with forest inventory data.

As described above, our model has great potential for application. This is because our model can be used only with the inputs of commonly available data for forest structure (i.e., $N$ and $d_{m}$ ) and meteorology (see Appendix B). Our model is specific to Japanese cedar and cypress plantations. However, our model is important in that it demonstrates how to relate $E$ with commonly available data. The concept of our model would be useful in developing similar models to estimate $E$ for mono-specific forests 
502

comprising other species.

On the other hand, the model needs to be tested further. The sites for cedar and cypress plantations (Table 1) were located mainly in western Japan, where temperature is intermediate or higher in the distribution areas of cedar and cypress (Japan Forestry Agency, 2013). We do not have enough $E$ data for cedar and cypress plantations recorded in regions where temperature is lower, except data for IK. The response of $G_{c}$ to temperature for stands in this region might be different from that observed in this study. We thus recommend testing the applicability of the model using data derived for sites located in this region. Furthermore, it is preferable to test the model applicability using data for sites with various age classes. Ages of the sites (Table 1) ranged between 19 and 99 years, which almost covers the age range for most Japanese cedar and cypress plantations in Japan (Japan Forestry Agency, 2013). However, many of the sites fall in the range of 40-60 years. Thus, applicability of our model has been tested sufficiently for stands within this age class, but has not been fully tested outside the age class. A major portion of Japanese cedar and cypress plantations in Japan falls in this age class, suggesting the practical usefulness of the model. On the other hand, the portion of older stands is expected to increase, because forestry in Japan has stagnated and cedar and cypress plantations have not been actively harvested (Komatsu et al., 2010). Therefore, we recommend testing the applicability of the model to stands outside the age class. 
522

523

524

525

526

527

528

529

530

531

532

534

535

536

537

538

539

540

541

\section{Acknowledgements}

We express our sincere thanks to members of Kyushu University Forest for their dedicated efforts in initiating the sites. We acknowledge Dr. Xinchao Sun (Graduate School of Life and Environmental Sciences, University of Tsukuba, Japan) for providing sapwood-area data for their site. Thanks are also due to two anonymous reviewers for providing critical comments. This research has been supported by a CREST project (Development of Innovative Technologies for Increasing Watershed Runoff and Improving River Environment by the Management Practice of Devastated Forest Plantation).

Appendix. A. Errors in interception evaporation estimates

The interception evaporation model developed by Komatsu et al. (2007a) and its revised form developed by Komatsu et al. (submitted) typically have an error of $4 \%$ of incident rainfall. The period with $T$ no less than $15{ }^{\circ} \mathrm{C}$ is typically April-October in regions where Japanese cedar and cypress are distributed and incident rainfall during the period is typically $1200 \mathrm{~mm}$ (National Astronomical Observatory, 2013). Annual rainfall in the regions is typically $1800 \mathrm{~mm}$. Thus, the typical error in interception evaporation estimates for the period with $T$ no less than $15^{\circ} \mathrm{C}$ would be $48 \mathrm{~mm}$, which was equivalent to $0.22 \mathrm{~mm} \mathrm{day}^{-1}$. The typical error for a year would be $72 \mathrm{~mm}$, which was equivalent to $0.20 \mathrm{~mm} \mathrm{day}^{-1}$. 
Appendix. B. Methods of preparing meteorological inputs

The model developed in this study requires daytime (6 a.m.-6 p.m.) mean solar

radiation $(R)$, temperature $(T)$, and vapor pressure deficit $(D)$ as meteorological inputs. $R$ data are not always available throughout Japan (Shinohara et al., 2007). It is often the case that only daily maximum $\left(T_{x}\right)$ and minimum temperatures $\left(T_{n}\right)$ are available for historical data (The University of Tokyo Forests, 2014). The former problem can be solved by substituting $R$ for the target area by data for solar radiation recorded at a meteorological observatory in surrounding areas. Data for daily solar radiation are recorded at main meteorological observatories in Japan (Japan Meteorological Agency, 2014). $R$ in units of $\mathrm{W} \mathrm{m}^{-2}$ can be approximated by daily solar radiation in units of $\mathrm{MJ} \mathrm{m}^{-2}$ day $^{-1}$ multiplied by an index of 23.1, which converts the units.

E during January 1-December 31, 2008 calculated using the model with the input of $R$, $T$, and $D$ observed at OL is $234 \mathrm{~mm}$. Here, $G_{c r e f}$ is assumed to be $0.00322 \mathrm{~m} \mathrm{~s}^{-1}$ on the basis of observed $A$ and the relationship between $A$ and $G_{c r e f}$ (Figure 6). $E$ values during the same period calculated with the input of solar radiation observed at meteorological observatories at Fukuoka, Saga, Oita, and Hiroshima are 238, 234, 237, and $240 \mathrm{~mm}$, respectively. These meteorological observatories are located 15, 50, 110, $200 \mathrm{~km}$ from 
562 are not important for estimating $E$ using the model. This is attributed to $E$ being 563 insensitive to $R$ when $R$ is high (Figure 2b) and $E$ on days with high $R$ accounting for a 564 relatively large portion of annual $E$. The latter problem (i.e., only $T_{x}$ and $T_{n}$ are available) can be solved making the following assumptions. First, the diurnal trend in temperature is approximated using a sine function minimized at 6 a.m. and maximized at 2 p.m. A simliar approximation has been commonly used to produce hourly temperature data from $T_{x}$ and $T_{n}$ (Campbell and Norman, 1998). Under this assumption, $T$ (i.e., temperature during 6 a.m. -6 p.m.) is analytically written as $T=\left(T_{x}+T_{n}\right) / 2+\left(T_{x}-T_{n}\right) /(3 \pi)$. Second, vapor pressure deficit at 6 a.m. is zero and daytime vapor pressure deficit is caused by a temperature rise during the day. Note that the assumption of vapor pressure deficit being zero in the morning is generally valid except in arid and semi-arid regions (Running et al., 1987; Kimball et al., 1994). $D$ (i.e., the mean vapor pressure deficit during 6 a.m. -6 p.m.) is thus approximated by $D=e_{s}(T)-e_{s}\left(T_{n}\right)$, where $e_{s}$ is the saturation vapor pressure. $E$ during January 1at $\mathrm{OL}$ is $225 \mathrm{~mm}$, which approximates $E$ calculated with the input of $T$ and $D$. Qualitatively, the same results are available for other sites. 
References

Adams, K.N., Fowler, A.M., 2006. Improving empirical relationships for predicting the effect of vegetation change on annual water yield. J. Hydrol. 321, 90-115.

Addington, R.N., Mitchell, R.J., Oren, R., Donovan, L.A., 2004. Stomatal sensitivity to vapor pressure deficit and its relationship to hydraulic conductance in Pinus palustris. Tree Physiol. 24, 561-569.

Bakan, D., 1966. The test of significance in psychological research. Psychol. Bull. 66, 423-437.

Baldocchi, D., Meyers, T.P., 1998. On using eco-physiological, micrometeorological and biogeochemical theory to evaluate carbon dioxide, water vapor and trace gas fluxes over vegetation: a perspective. Agric. For. Meteorol. 90, 1-25.

Bosch, J.M., Hewlett, J.D., 1982. A review of catchment experiments to determine the effect of vegetation changes on water yield and evapotranspiration. J. Hydrol. 55, 323.

Bréda, N.J.J., 2003. Ground-based measurements of leaf area index: a review of methods, instruments and current controversies. J. Exp. Bot. 54, 2403-2417.

Brown, A., Zhang, L., McMahon, T.A., Western, A.W., Vertessy, R.A., 2005. A review of paired catchment studies for determining changes in water yield resulting from alterations in vegetation. J. Hydrol. 310, 28-61.

Campbell, G.S., Norman, J.M., 1998. An Introduction to Environmental Biophysics. 
Springer-Verlag, New York.

601

602

603

604

605

606

607

608

609

610

Cienciala, E., Eckersten, H., Lindroth, A., Hallgren, J., 1994a. Simulated and measured water uptake by Picea abies under non-limiting soil water conditions. Agric. For. Meteorol. 71, 147-164.

Cienciala, E., Lindroth, A., Cermak, J., Hallgren, J., Kucera, J., 1994b. The effects of water availability on transpiration, water potential and growth of Picea abies during a growing season. J. Hydrol. 155, 57-71.

Cornish, P.M., Vertessy, R.A., 2001. Forest age-induced changes in evapotranspiration and water yield in a eucalypt forest. J. Hydrol. 242, 43-63.

Dawson, T.E., Burgess, S.S.O., Tu, K.P., Oliveira, R.S., Santiago, L.S., Fisher, J.B., Simonin, K.A., Ambrose, A.R., 2007. Nighttime transpiration in woody plants from contrasting ecosystems Tree Physiol. 27, 561-575.

Diadonis, P., Efron, B., 1983. Computer-intensive methods in statistics. Sci. Am. 248, 116-131.

Domec, J.C., Ogée, J., Noormets, A., Jouangy, J., Gavazzi, M., Treasure, E., Sun, G., McNulty, S.G., King, J.S., 2012. Interactive effects of nocturnal transpiration and climate change on the root hydraulic redistribution and carbon and water budgets of southern United States pine plantations. Tree Physiol. 32, 707-723.

Dung, B.X., Gomi, T., Miyata, S., Sidle, R.C., Kosugi, K., Onda, Y., 2012. Runoff responses to forest thinning at plot and catchment scales in a headwater catchment 
draining Japanese cypress forest. J. Hydrol. 444-445, 51-62.

621

Efron, B., 1979. Bootstrap methods: another look at the Jacknife. Ann. Stat. 7, 1-26.

622

Efron, B., 1987. Better bootstrap confidence intervals. J. Amer. Statis. Assoc. 82, 171185.

Ewers, B.E., Oren, R., 2000. Analyses of assumptions and errors in the calculation of stomatal conductance from sap flux measurements. Tree Physiol. 20, 579-589.

Ewers, B.E., Mackay, D.S., Tang, J., Bolstad, P.V., Samanta, S., 2008. Intercomparison of Meteorol. 148, 231-246.

630

Forrester, D.I., Collopy, J.J., Morris, J.M., 2010. Transpiration along an age series of 
640 Fox, J., 2008. Applied Regression Analysis and Generalized Linear Models. Sage 641 Publications, Thousand Oaks, Carfornia.

642

643

644

645

646

647

648

649

650

651

652

653

654

655

656

657

658

659

Franzer, G.W., Ganha, C.D., Lerzman, K.P., 1999. Gap Light Analyzer (GLA) Version 2.0: Image software to Extract Canopy Structure and Gap Light Transmission Indices from True-colour Fisheye Photographs. Simon Franser University, British Columbia, and the Institute of Ecosystem Studies, Millbrook, NewYork, pp. 1-36.

Fujii, H., 2005. Practical Methods of Data Analysis for Engineers. Tokyo-Kagaku-Dojin, Tokyo.

Granier, A., 1987. Evaluation of transpiration in a Douglas-fir stand by means of sap flow measurements. Tree Physiol. 3, 309-320.

Granier, A., Bréda, N., 1996. Modelling canopy conductance and stand transpiration of an oak forest from sap flow measurements. Ann. Sci. For. 53, 537-546.

Granier, A., Loustau, D., Bréda, N., 2000a. A generic model of forest canopy conductance dependent on climate, soil water availability and leaf area index. Ann. For. Sci. 57, 755-765.

Granier, A., Biron, P., Lemoine, D., 2000b. Water balance, transpiration and canopy conductance in two beech stands. Agric. For. Meteorol. 100, 291-308.

Hasegawa, K., Omi, H., Hiruma, Y., Kumagai, S., Yamamoto, R., Izumi, T., Matsuyama, H., 2013. Estimation of leaf area index of Cryptomeria japonica using various methods : A case study of Aso District, Kumamoto Prefecture. J. Geograph. 122, 875- 
Hattori, S., Chikaarashi, H., Takeuchi, N., 1982. Measurement of the rainfall interception and its micrometeorological analysis in a Hinoki stand. Bull. FFPRI 318, 79-102.

Ichihashi, R., Komatsu, H., Kume, T., Onozawa, Y., Shinohara, Y., Tsuruta, K., Otsuki, K., Stand-scale transpiration of two Moso bamboo stands with different culm densities. Ecohydrol. In press.

Japan Forestry Agency, 2013. White Paper for Forest and Forestry. Japan Forestry Agency, Tokyo. (Available at: http://www.rinya.maff.go.jp/j/kikaku/hakusyo/index.html).

Japan Forestry Agency, 2014. Data for Japanese cedar and cypress plantations. http://www.rinya.maff.go.jp/j/sin_riyou/kafun/data.html. http://www.jma.go.jp/jma/menu/report.html. conductance found in canopies in the field. Phil. Trans. R. Soc. Lond. B 273, 593-610. Jarvis, P.G., McNaughton, K.G., 1986. Stomatal control of transpiration: scaling up from leaf to region. Adv. Ecol. Res. 15, 1-49.

Kimball, J.S., Running, S.W., Nemani, R. 1994. An improved method for estimating surface humidity from daily minimum temperature. Agric. For. Meteorol. 85, 87-98.

Komatsu, H., 2004. A general method of parameterizing the big-leaf model to predict the dry-canopy evaporation rate of individual coniferous forest stands. Hydrol. Process. 
18, 3019-3036.

681

682

683

684

685

686

Komatsu, H., Kang, Y., Kume, T., Yoshifuji, N., Hotta, N., 2006. Transpiration from a Cryptomeria japonica plantation, part 2: responses of canopy conductance to meteorological factors. Hydrol. Process. 20, 1321-1334.

Komatsu, H., Tanaka, N., Kume, T., 2007a. Do coniferous forests evaporate more water than broad-leaved forests in Japan? J. Hydrol. 336, 361-375.

Komatsu, H., Hotta, N., Kume, T., 2007b. What is the best way to represent surface conductance for a range of vegetated sites? Hydrol. Process. 21, 1142-1147.

Komatsu, H., Katayama, A., Hirose, S., Kume, A., Higashi, N., Ogawa, S., Otsuki, K., 2007c. Reduction in soil water availability and tree transpiration in a forest with pedestrian trampling. Agric. Forest Meteorol. 146, 107-114.

Komatsu, H., Kume, T., Otsuki, K., 2007d. Contemporary role of catchment water balance data for forest evapotranspiration research. J. Jpn. For. Soc. 89, 346-359.

Komatsu, H., Kume, T., Otsuki, K., 2010. Water resource management in Japan-forest management or dam reservoirs? J. Environ. Manage. 91, 814-823.

Komatsu, H., Kume, T., Otsuki, K., 2011. Increasing annual runoff-broadleaf or coniferous forests? Hydrol. Process. 25, 302-318.

Komatsu, H., Onozawa, Y., Kume, T., Tsuruta, K., Shinohara, Y., Otsuki, K., 2012. Canopy conductance for a Moso bamboo (Phyllostachys pubescens) forest in western Japan. Agric. For. Meteorol. 156, 111-120. 
Komatsu, H., Shinohara, Y., Nogata, M., Tsuruta, K., Otsuki, K., 2013. Changes in canopy transpiration due to thinning of a Cryptomeria japonica plantation. Hydrol. Res. Lett. 7, 60-65.

Komatsu, H., Shinohara, Y., Otsuki, K., Models to predict changes in annual runoff with thinning and clearcutting of Japanese cedar and cypress plantations in Japan.

Kosugi, Y., Kobashi, S., Shibata, S., 1995. Modeling stomatal conductance on leaves of several temperate evergreen broad-leaved trees. J. Jap. Reveget. Tech. 20, 158-167.

Kosugi, Y., Shibata, S., Matsui, K., Kobashi, S., 1997. Differences between deciduous

Kosugi, Y., Takanashi, S., Tanaka, H., Ohkubo, S., Tani, M., Yano, M., Katayama, T., 2007. Evapotranspiration over a Japanese cypress forest. I. Eddy covariance fluxes and surface conductance characteristics for 3 years. J. Hydrol. 337, 269- 283.

Kubota, T., Tsuboyama, Y., Nobuhiro, T., Sawano, S., 2013. Change of evapotranspiration due to stand thinning in the Hitachi Ohta Experimental Watershed. J. Jpn. For. Soc. 95, $37-41$.

Kumagai, T., Aoki, S., Nagasawa, H., Mabuchi, T., Kubota, K., Inoue, S., Utsumi, Y. and 
transpiration in Japanese cedar. Agric. For. Meteorol. 135, 110-116.

721

722

723

724

725

726

727

728

729

730

731

732

733

Kumagai, T., Aoki, S., Shimizu, T., Otsuki, K., 2007. Sap flow estimates of stand transpiration at two slope positions in a Japanese cedar forest watershed. Tree Physiol. 27, 161-168.

Kumagai, T., Tateishi, M., Shimizu, T., Otsuki, K., 2008. Transpiration and canopy conductance at two slope positions in a Japanese cedar forest watershed. Agric. For. Meteorol. 148, 1444-1455.

Kumagai, T., Tateishi, M., Miyazawa, Y., Kobayashi, M., Yoshifuji, N., Komatsu, H., Shimizu, T., 2014. Estimation of annual forest evapotranspiration from a coniferous plantation watershed in Japan (1): Water use components in Japanese cedar stands. J. Hydrol. 508, 66-76.

Kume, T., Tsuruta, K., Komatsu, H., Kumagai, T., Higashi, N., Shinohara, Y., Otsuki, K., 2010. Effects of sample size on sap flux-based stand-scale transpiration estimates Tree Physiol. 30, 129-138.

Kume, T., Tsuruta, K., Komatsu, H., Shinohara, Y., Katayama, A., Ide, J., Otsuki, K., Differences in sap flux based stand transpiration between upper and lower slope positions in a Japanese cypress plantation watershed. Submitted to J. Hydrol.

Laplace 2013. Study on Transpiration in a Taiwanese Moso Bamboo Forest using Sap Flow Measurement. Master thesis, National Taiwan University.

Lohammer, T., Linder, S., Falk, O., 1980. FAST-simulation models of gaseous exchange 
in Scots. Pine. Ecol. Bull. (Stockholm) 32, 505-523.

741

742

743

744

745

746

747

Loustau, D., Berbigier, P., Roumagnac, P., Arruda-Pacheco, C., David, J.S., Ferreira, M.I., Pereira, J.S., Tavares, R., 1996. Transpiration of a 64-year-old maritime pine stand in Portugal. 1. Seasonal course of water flux through maritime pine. Oecologia 107, 3342.

Macfarlane, C., Bond, C., White, D.A., Grigg, A.H., Ogdena, G.N., Silberstein, R., 2010. Transpiration and hydraulic traits of old and regrowth eucalypt forest in southwestern Australia. Forest Ecol. Manage. 260, 96-105.

Mackay, D.S., Ewers, B.E., Loranty, M.M., Kruger, E.L., 2010. On the representativeness of plot size and location for scaling transpiration from trees to a stand. J. Geophys. Res. 115, G02016.

McDowell, N.G., Fisher, R.A., Xu, C., Domec, J.C., Hölttä, T., Mackay, D.S., Sperry, J.S., Boutz, A., Dickman, L., Gehres, N., Limousin, J.M., Macalady, A., Martínez-Vilata, J., Mencuccini, M., Plaut, J.A., Ogée, J., Pangle, R.E., Rasse, D.P., Ryan, M.G., Sevanto, S., Waring, R.H., Williams, A.P., Yepez, E.A., Pockman, W.T., 2013. Evaluating theories of drought-induced vegetation mortality using a multimodelexperiment framework. New Phytol. 200, 304-321.

McNaughton, K.G., Black, T.A., 1973. A study of evapotranspiration from a Douglas fir forest using the energy balance approach. Water Resour. Res. 9, 1579-1590.

National Astronomical Observatory, 2013. Chronological Scientific Tables 2014. 
Maruzen, Tokyo.

761 Nuzzo, R., 2014. Statistical errors. Nature 506, 150-152.

762 Oishi, A.C., Oren, R., Stoy, P.C., 2008. Estimating components of forest 
grandis and Pinus petula and to felling in the Mokobulaan experimental catchments,

782

Shinohara, Y., Komatsu, H., Otsuki, K., 2007. A method for estimating global solar radiation from daily maximum and minimum temperatures: Its applicability to Japan. J. Jpn. Soc. Hydrol. Water Resour. 20, 462-469.

Shinohara, Y., Tsuruta, K., Ogura, A., Noto, F., Komatsu, H., Otsuki, K., Maruyama, T., 2013a. Azimuthal and radial variations in sap flux density and effects on stand-scale transpiration estimates in a Japanese cedar forest. Tree Physiol. 33, 550-558.

Shinohara, Y., Tsuruta, K., Kume, T., Otsuki, K., 2013b. An overview of stand-scale transpiration measurements using the sap flow technique for evaluating the effects of forest management practices. J. Jpn. For. Soc. 95, 321-331.

Stewart, J.B., Thom, A.S., 1973. Energy budgets in pine forest. Quart. J. Roy. Met. Soc. 99, 154-170.

Sun, X., Onda, Y., Kato, H., Otsuki, K., Gomi, T., 2014. Partitioning of the total evapotranspiration in a Japanese cypress plantation during the growing season. Ecohydrol. 7, 1042-1053.

Suzuki, M., 1980. Evapotranspiratoin from a small catchment in hilly mountains (I) Seasonal variations in evapotranspiration, rainfall interception and transpiration. J. Jpn. For. Soc. 62, 46-53.

Tanaka, K., Tanaka, H., Nakamura, A., Ohte, N., Kobashi, S., 1996. Conductance at a 
community level and characteristics of $\mathrm{CO}_{2}$ exchange in hinoki (Chamaecyparis obtusa) stand. J. Jpn. For. Soc. 78, 266-272.

Tanaka, K., Kosugi, Y., Nakamura, A., 2002. Impact of leaf physiological characteristics on seasonal variation in $\mathrm{CO}_{2}$, latent and sensible heat exchanges over a tree plantation. Agric. For. Meteorol. 114, 103-122.

Tanaka, N., Kuraji, K., Shiraki, K., Suzuki, Y., Suzuki, M., Ohta, T., Suzuki, M., 2005. Throughfall, stemflow and rainfall interception at mature Cryptomeria japonica and Chamaecyparis obtusa stands in Fukuroyamasawa watershed. Bull. Tokyo Univ. Forest 113, 197-240.

The University of Tokyo Forests, 2014. Meteorological data. http://www.uf.a.utokyo.ac.jp/eri/public.html.

Thompson, B., 1996. AERA editorial policies regarding statistical significance testing: three suggested reforms. Educational Res. 25, 26-30.

Thompson, B., 1998. Statistical significance and effect size reporting: Portrait of a possible future. Res. Sch. 5, 33-38.

Tsuruta, K., Kume, T., Komatsu, H., Higashi, N., Kumagai, T., Otsuki, K., 2008. Relationship between tree height and transpiration for individual Japanese Cypress (Chamaecyparis obtusa). J. Jpn. Soc. Hydrol. Water Resour. 21, 414-422. Allometric equations between stem diameter and sapwood area of Japanese cedar and 
Japanese cypress for stand transpiration estimates using sap flow measurement. J. Jpn.

Tsuruta, K., Nogata, M., Shinohara, Y., Komatsu, H., Otsuki, K., 2014. The correction coefficient for leaf area index measurement based on the optical method in a Japanese cedar (Cryptomeria japonica) forest. Bull. Kyushu Univ. For. Accepted.

Tsuruta, K., Komatsu, H., Kume, T., Shinohara, Y., Otsuki, K., Canopy transpiration in 826 two Japanese cypress forests with contrasting structures. Submitted to J. For. Res. Japanese cypress and Japanese cedar plantations due to selective thinning. Submitted to Hydrol. Process. 228.

Zwieniecki, M.A., Holbrook, N.M., 1998. Diurnal variation in xylem hydraulic conductivity in white ash (Fraxinus americana L.), red maple (Acer rubrum L.) and red spruce (Picea rubens Sarg.). Plant, Cell Environ. 21, 1173-1180. 
Figure captions

837 Figure 1. Relationships (a) between vapor pressure deficit $(D)$ and canopy conductance

$838\left(G_{c}\right)$, (b) between solar radiation $(R)$ and $G_{c}$ divided by $G_{c r e f} f(D)$, and (c) between 839 temperature $(T)$ and $G_{c}$ divided by $G_{c r e f} f(D) g(R)$ for the OL site. Solid lines in Figures 1a, 8401 b, and 1c indicate $f(D), g(R)$, and $h(T)$ for OL, respectively. $G_{c r e f}$ is the reference value 841 of canopy conductance. $f(D), g(R)$, and $h(T)$ are functions expressing the responses of $G_{c}$ 842 to $D, R$, and $T$.

Figure 2. Functions expressing the responses of canopy conductance to (a) vapor pressure deficit $(f(D))$, (b) solar radiation $(g(R))$, and (c) temperature $(h(T))$ for each site.

Figure 3. Relationships of the mean transpiration $(E)$ for days with no rain and temperature being no less than $15^{\circ} \mathrm{C}$ (i.e., corresponding to a growing season) calculated using (a) P1G, (b) P2G, and (c) P3G with the mean observed E. Here, P1G, P2G, and P3G respectively use the mean values of $G_{c r e f}, \beta$, and $\delta$ among the sites, $G_{c r e f}$ determined for each site and the mean values of $\beta$ and $\delta$ among the sites, and $G_{c r e f}, \beta$, and $\delta$ determined for each site. The solid line indicates the 1:1 relationship. Dotted lines indicate conditions that errors in $E$ estimates equal potential errors in observed $E$. Error bars indicate standard deviations. 
856 Figure 4. Relationships of the mean transpiration $(E)$ for days with no rain calculated

857 using (a) P1W, (b) P2W, and (c) P3W with the mean observed $E$ for sites having data

858 recorded in winter as well as those recorded in a growing season. Here, P1W, P2W, and

859 P3W respectively use the mean values of $G_{c r e f}, \beta, \delta$, $\varepsilon$, and $\zeta$ among the sites, $G_{c r e f}$ 860 determined for each site and the mean values of $\beta, \delta, \varepsilon$, and $\zeta$ among the sites, and $G_{c r e f}$, $861 \beta, \delta, \varepsilon$, and $\zeta$ determined for each site. The solid line indicates the 1:1 relationship. Dotted 862 lines indicate conditions that errors in $E$ estimates equal potential errors in observed $E$. 863 Error bars indicate standard deviations.

864

Figure 5. Time series of daily transpiration $(E)$ calculated using P1W, P2W, and P3W and observed $E$ for OU. Lines for P2W and P3W overlap each other. E observed on rainy days is not plotted in this figure.

Figure 6. Relationship between the sapwood area at a stand scale $(A)$ and the reference value of canopy conductance $\left(G_{c r e f}\right)$. The regression line for the relationship between $A$ and $G_{c r e f}$, determined using the least-squares method, is written as $y=0.157 x$.

Figure 7. Normal probability plot for the difference between estimated and observed reference values of canopy conductance $\left(G_{c r e f}\right)$. The solid line is the regression line, determined using the least-squares method, for all data except those for SK and IK. 
876

877 Figure 8. Comparison between estimated and observed sapwood areas on a stand scale

878 (A). The solid line indicates the 1:1 relationship.

879

880 Figure 9. Time series of daily transpiration $(E)$ calculated using $\mathrm{P} 2 \mathrm{~W}$ by omitting 881 functions expressing the responses of $G_{c}$ to (a) vapor pressure deficit $(f(D))$, (b) solar 882 radiation $(g(R))$, and (c) temperature $(h(T))$. 


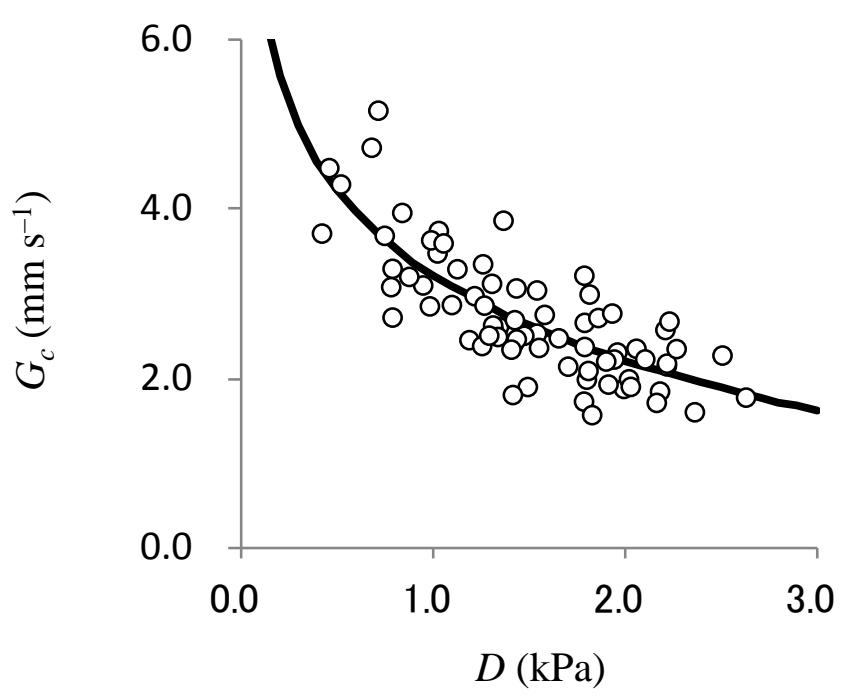

(a)

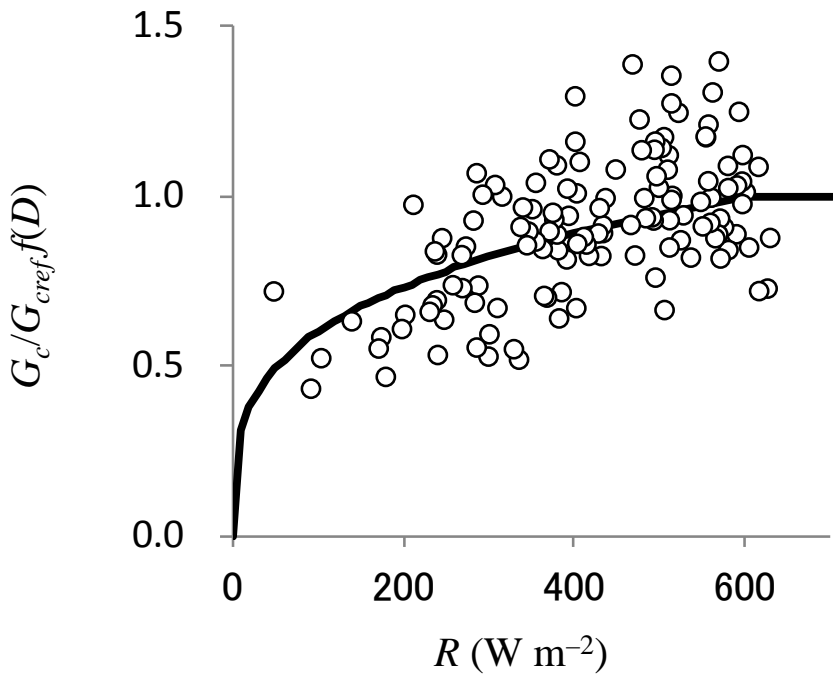

(b)

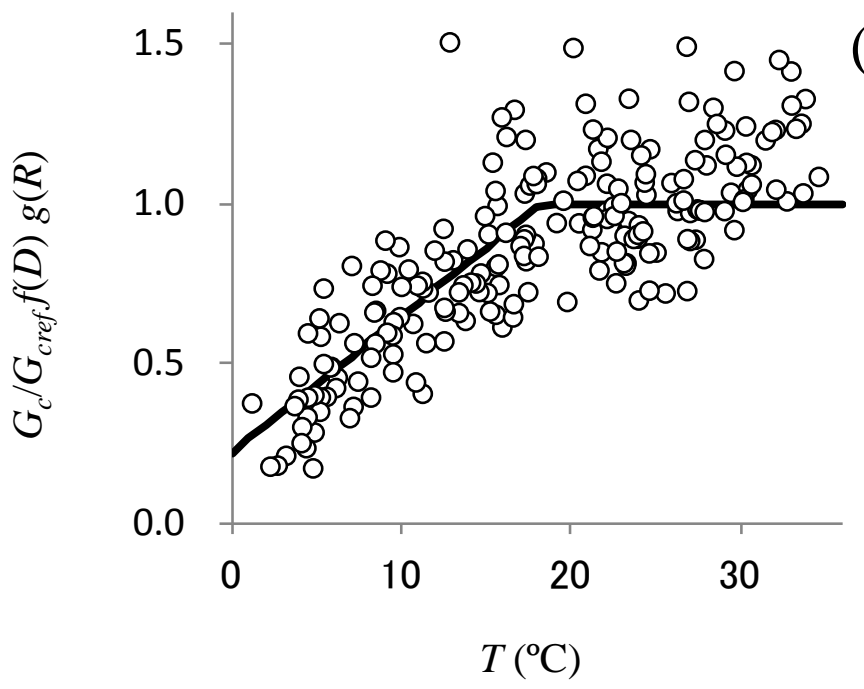

(c) 


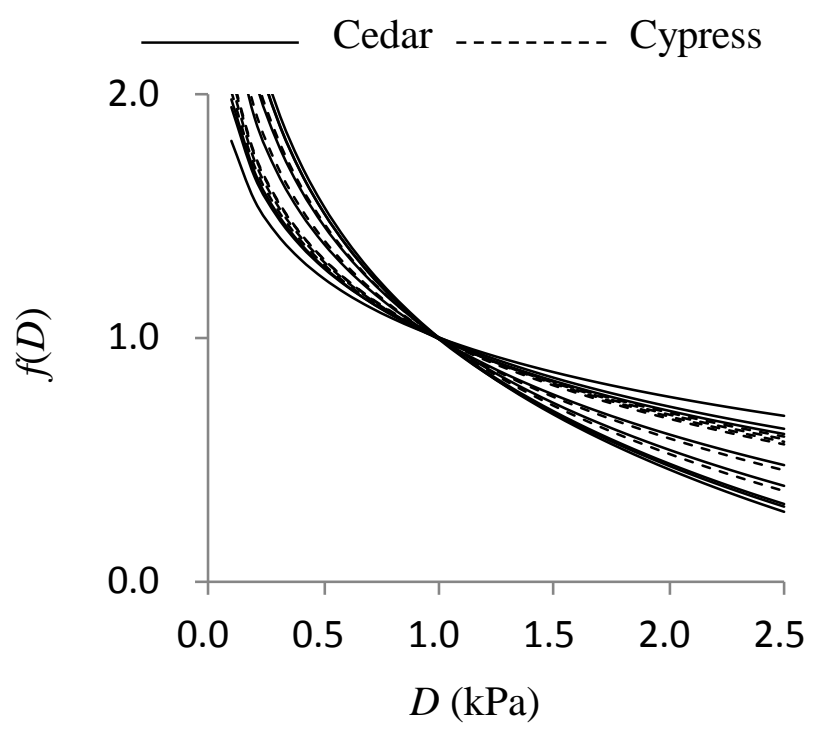

(a)
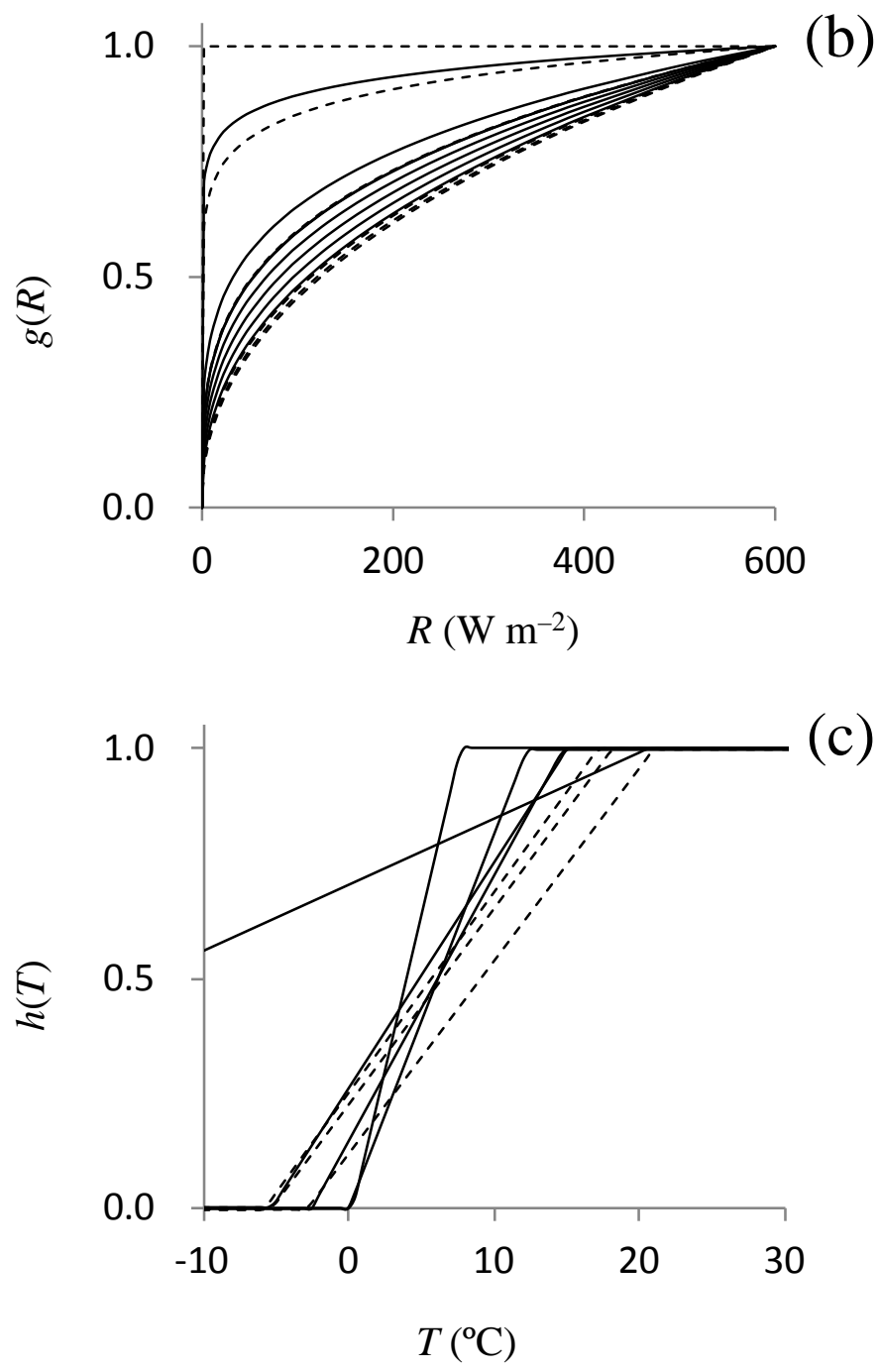

Figure 2 
- Cedar $\Delta$ Cypress

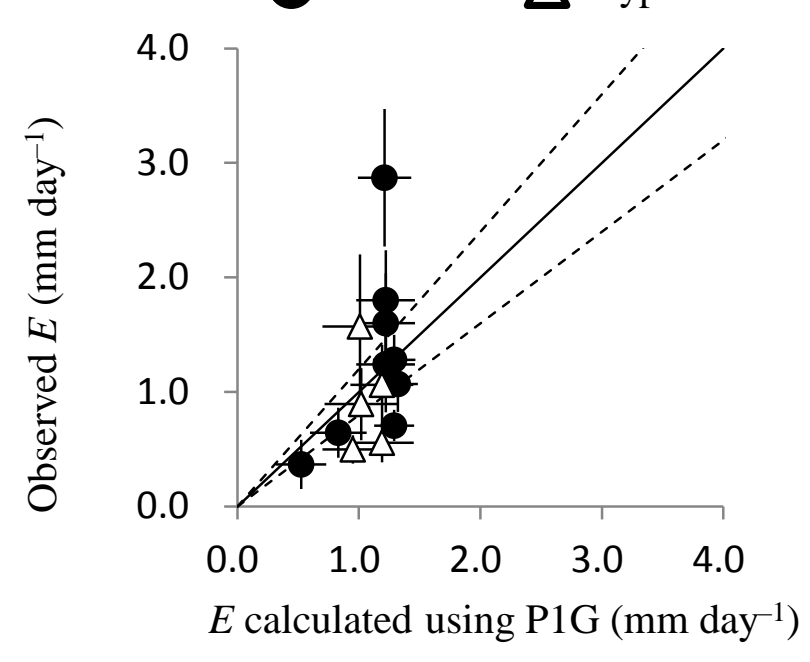

(a)

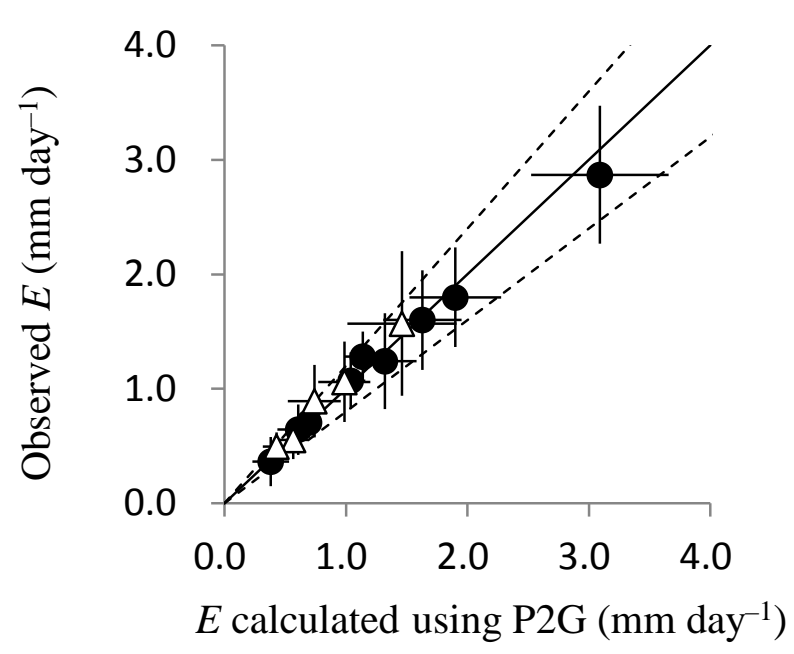

(b)

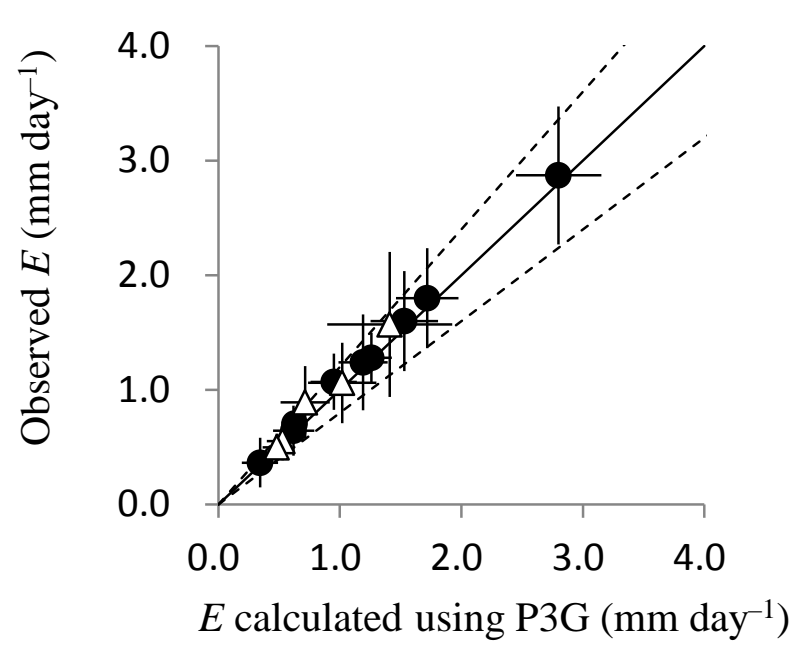

(c) 
Cedar $\Delta$ Cypress

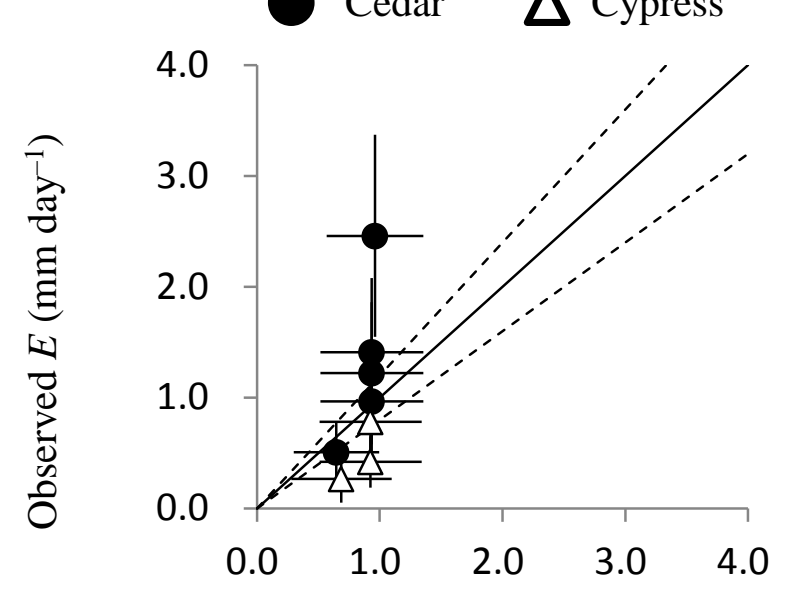

(a)

$E$ calculated using P1W (mm day $\left.{ }^{-1}\right)$

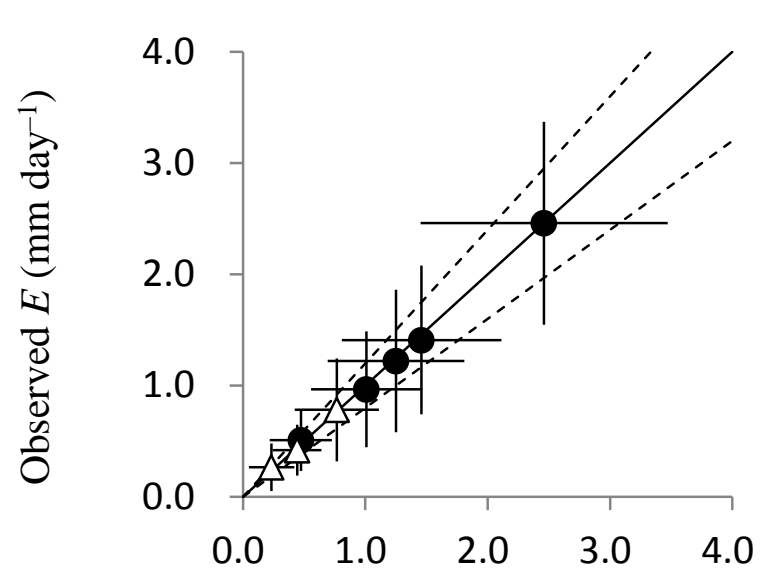

(b)

$E$ calculated using P2W (mm day $\left.{ }^{-1}\right)$

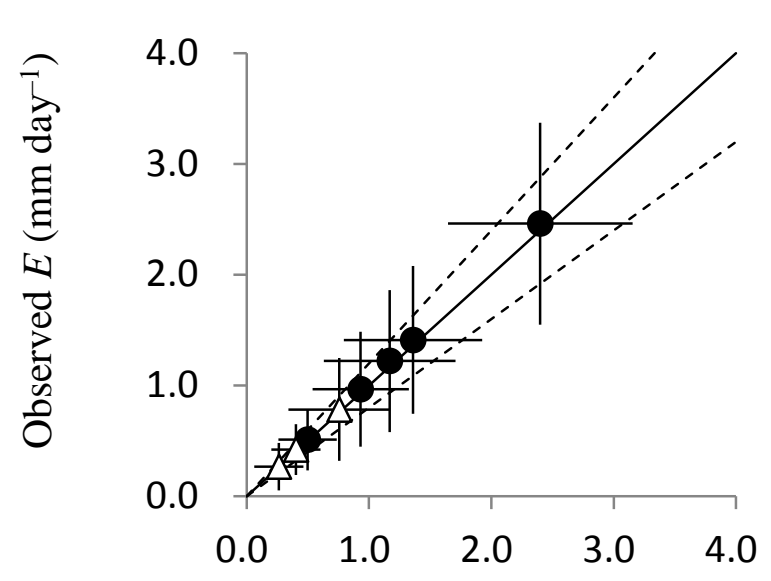

(c)

$E$ calculated using P3W (mm day $\left.{ }^{-1}\right)$ 


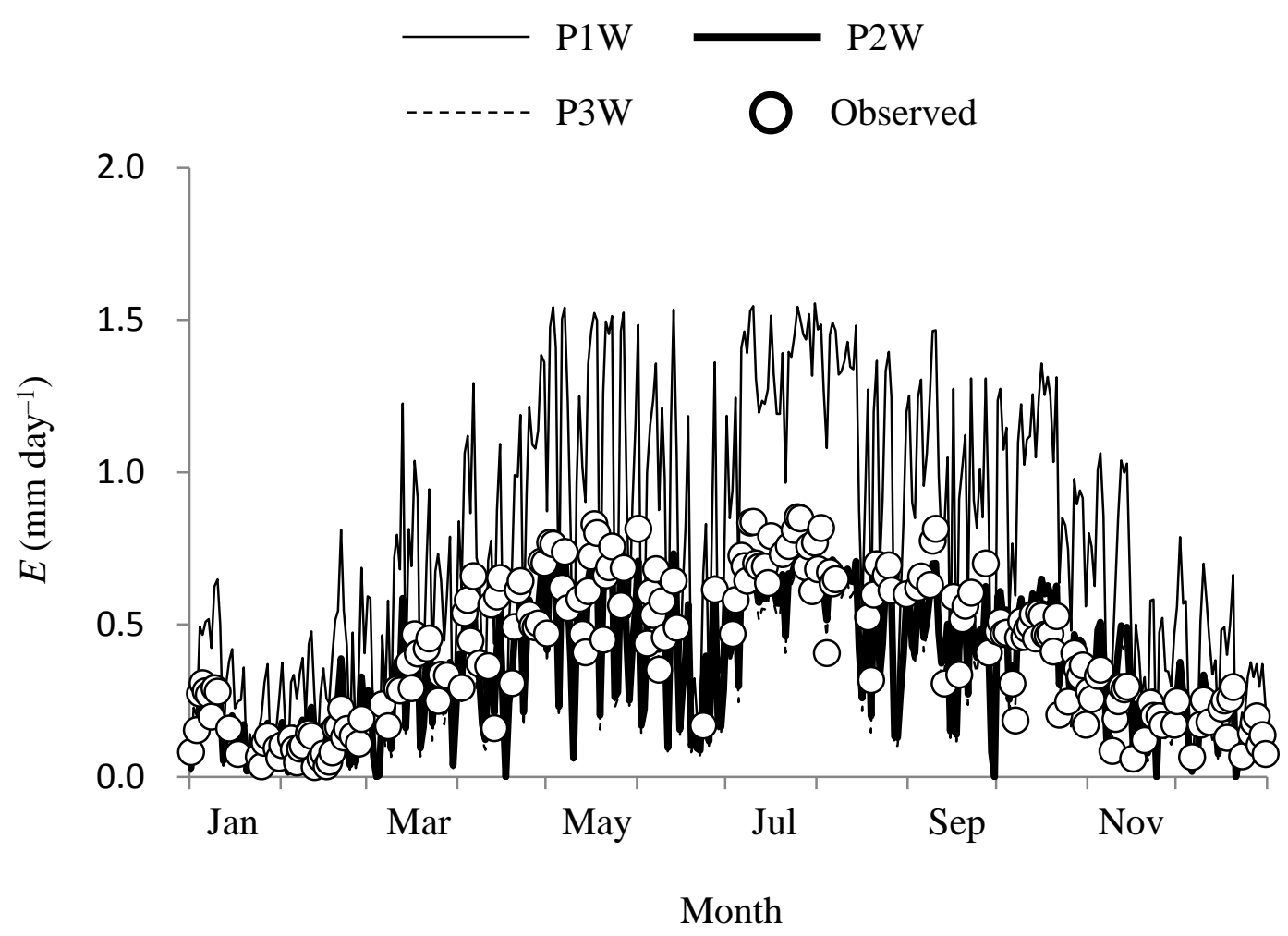

Figure 5 


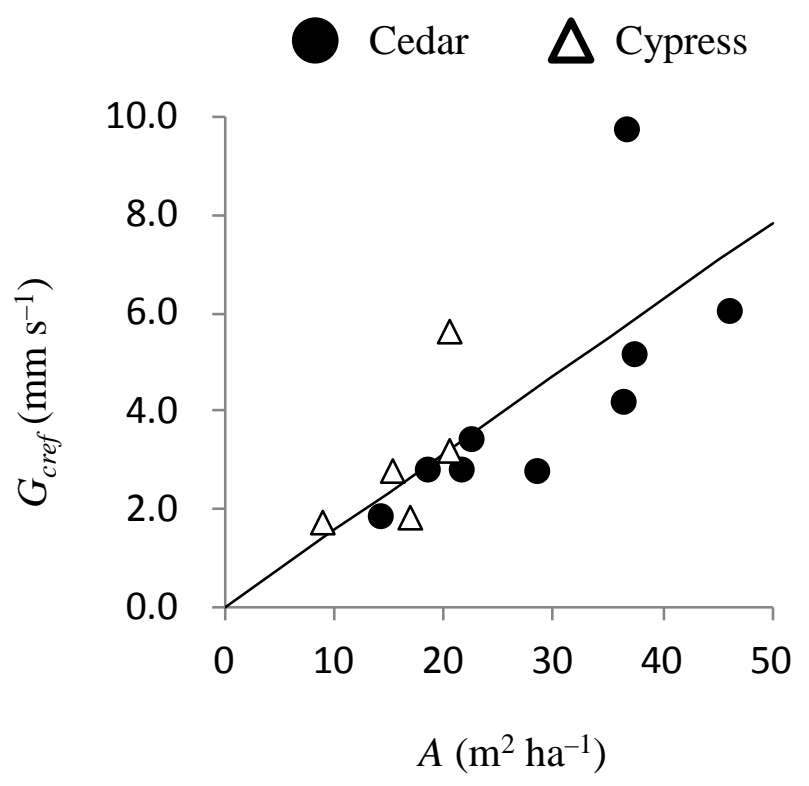

Figure 6 


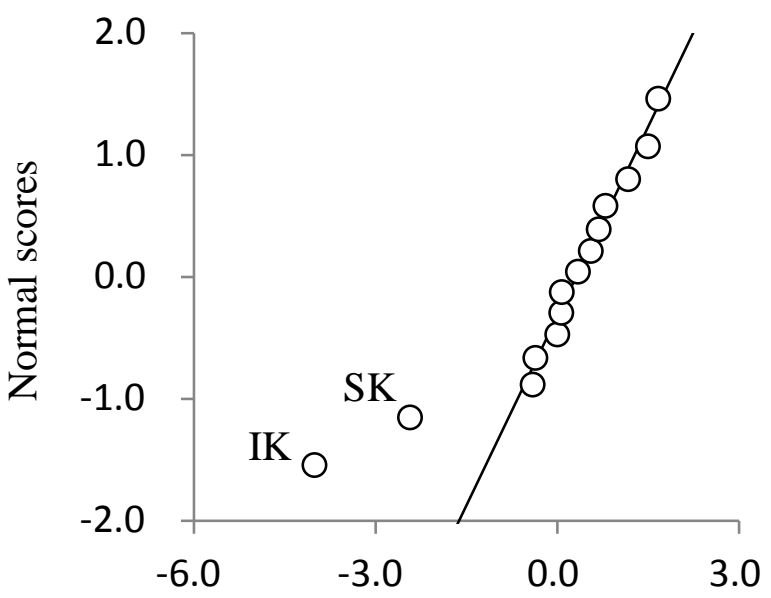

Estimated minus observed $G_{c r e f}\left(\mathrm{~mm} \mathrm{~s}^{-1}\right)$ 
Cedar $\Delta$ Cypress

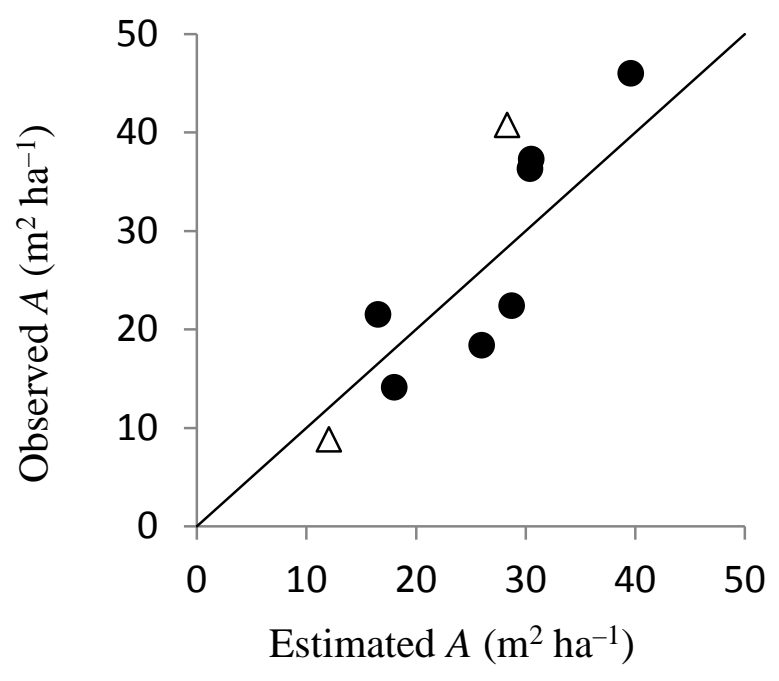

Figure 8 
Calculated $\quad \mathrm{O}$ Observed
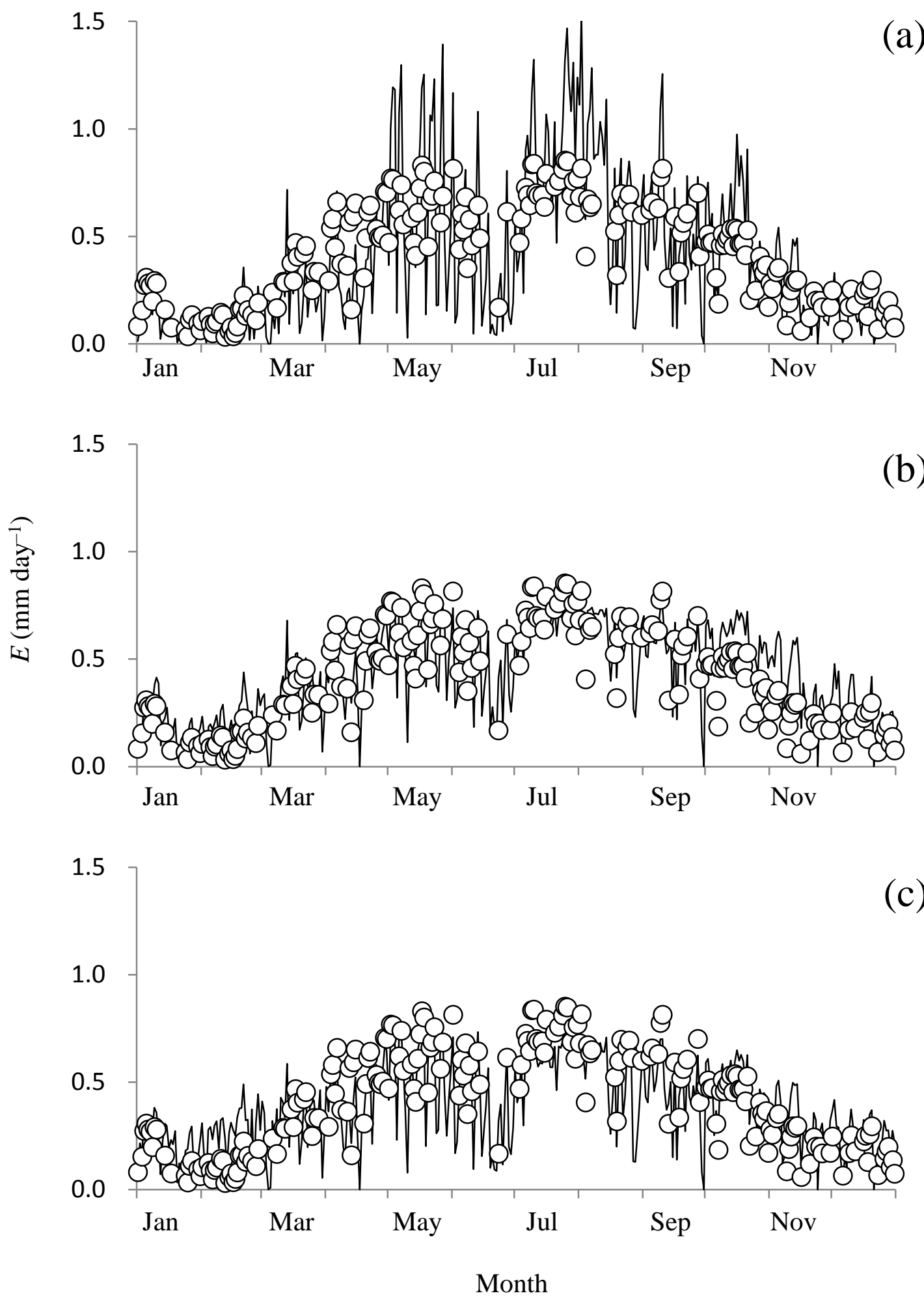

Figure 9 
Table 1. Location, meteorology (the mean annual rainfall $P$ and temperature $T$ ), structure (stem density $N$, the mean diameter at breast height $d_{m}$, leaf area index $L$, and sapwood area $A$ ), and description of sap-flux measurements for the plantation sites

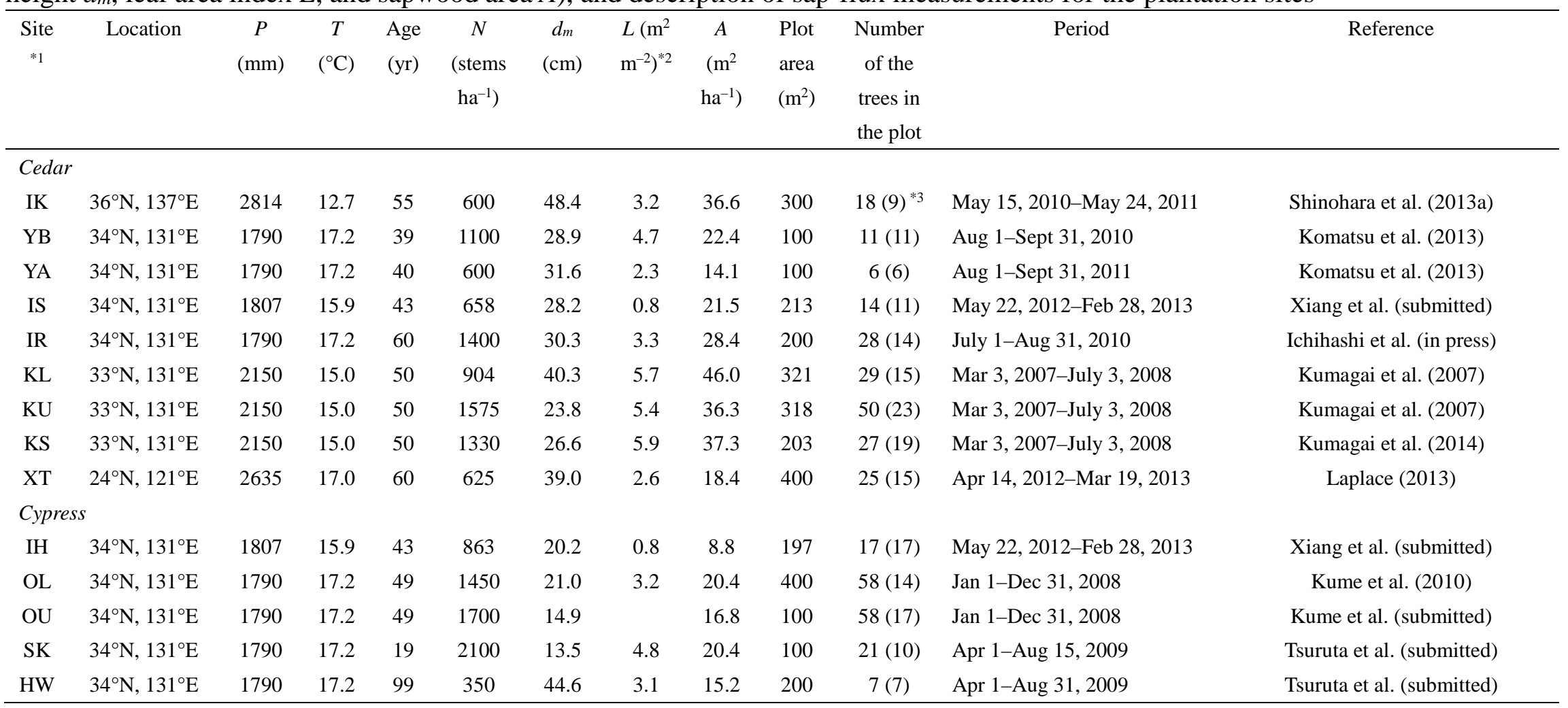

${ }^{* 1}$ The original names of the sites are given as follows. IK: Ishikawa-ken Forest Experimental Station, YB: Yamanokami site (before thinning), YA: Yamanokami site (after thinning), IS: Yayama Experimental Catchment (cedar) in Iizuka, IR: Ichirinpan Plot in the Kasuya Research Forest, KU: UP of Kahoku Experimental Watershed, KL: LP of Kahoku Experimental Watershed, KS: SP of Kahoku Experimental Watershed, XT: Xitou Experimental Forest, IH: Yayama Experimental Catchment (cypress) in Iizuka, OL: Riparian Plot of Ochozu Experimental Watershed, OU: Ridge Plot of Ochozu Experimental Watershed, SK: Sakuta Plot in Kasuya Research Forest, HW: Hiawada Plot in Kasuya Research Forest

${ }^{* 2} L$ for all sites except OL and IK was measured using a plant-canopy analyzer (LAI-2000, Li-Cor Inc., Lincoln, Nebraska, USA). $L$ for OL and IK was measured using a digital nonspherical color photograph and Gap Light Analyzer software (Franzer et al., 1999).

${ }^{* 3}$ Numerals in the parentheses indicate the number of trees in which sensors were installed. 
Table 2. Parameter values optimized for each site

\begin{tabular}{|c|c|c|c|c|c|c|c|c|}
\hline Site & $G_{c r e f}\left(\mathrm{~mm} \mathrm{~s}^{-1}\right)$ & $\beta$ in $f(D)$ & $R^{2}$ & $\delta$ in $g(R)$ & $R^{2}$ & $\varepsilon\left({ }^{\circ} \mathrm{C}\right)$ in $h(T)$ & $\zeta\left({ }^{\circ} \mathrm{C}\right)$ in $h(T)$ & $R^{2}$ \\
\hline \multicolumn{9}{|l|}{ Cedar } \\
\hline IK & 9.77 & 0.750 & 0.782 & 0.287 & 0.389 & 7.75 & 0.313 & 0.469 \\
\hline YB & 3.46 & 0.441 & 0.493 & $0.0893^{* 1}$ & 0.00793 & & & \\
\hline YA & 1.89 & 0.427 & 0.365 & $0.0625^{* 1}$ & 0.00247 & & & \\
\hline IS & 2.84 & 0.569 & 0.580 & 0.238 & 0.339 & 20.7 & -48.8 & 0.164 \\
\hline IR & 2.81 & 0.351 & 0.214 & 0.288 & 0.219 & & & \\
\hline KL & 6.07 & 0.783 & 0.605 & 0.347 & 0.316 & 12.3 & 0.065 & 0.587 \\
\hline KU & 4.22 & 0.749 & 0.438 & 0.410 & 0.240 & 15.1 & -5.22 & 0.343 \\
\hline KS & 5.19 & 0.667 & 0.628 & 0.378 & 0.392 & 14.8 & -2.49 & 0.544 \\
\hline $\mathrm{XT}$ & 2.84 & 0.412 & 0.213 & 0.308 & 0.310 & & & \\
\hline \multicolumn{9}{|l|}{ Cypress } \\
\hline $\mathrm{IH}$ & 1.76 & 0.472 & 0.622 & $0.000^{* 1}$ & -0.0329 & 21.0 & -2.84 & 0.740 \\
\hline OL & 3.22 & 0.453 & 0.628 & 0.285 & 0.330 & 18.2 & -5.19 & 0.636 \\
\hline OU & 1.86 & 0.591 & 0.738 & 0.417 & 0.561 & 17.2 & -5.78 & 0.584 \\
\hline SK & 5.65 & 0.468 & 0.412 & 0.432 & 0.252 & & & \\
\hline HW & 2.81 & 0.688 & 0.436 & 0.441 & 0.270 & & & \\
\hline Mean & 3.89 & 0.556 & & 0.285 & & 15.9 & -8.74 & \\
\hline Standard deviation & 2.19 & 0.146 & & 0.142 & & 4.43 & 16.4 & \\
\hline
\end{tabular}

${ }^{* 2}$ A small $\delta$ value does not suggest that there was no effect of solar radiation on transpiration, but suggests that the effect was not detectable by an analysis on a daily time scale. 
Table 3. Slope and coefficient of determination $\left(R^{2}\right)$ for the relationship between calculated and observed transpiration.

\begin{tabular}{ccccccc}
\hline Site & \multicolumn{2}{c}{ P1W } & \multicolumn{2}{c}{ P2W } & \multicolumn{3}{c}{ P3W } \\
& Slope $^{* 1}$ & $R^{2}$ & Slope & $R^{2 * 2}$ & Slope & $R^{2}$ \\
\hline Cedar & & & & & & \\
IK & 2.43 & $0.329 * 3$ & 0.946 & 0.329 & 1.02 & 0.576 \\
IS & 0.776 & 0.867 & 1.06 & 0.867 & 1.03 & 0.874 \\
KL & 1.50 & 0.845 & 0.964 & 0.845 & 1.04 & 0.818 \\
KU & 1.05 & 0.757 & 0.970 & 0.757 & 1.06 & 0.726 \\
KS & 1.32 & 0.848 & 0.988 & 0.848 & 1.05 & 0.845 \\
Cypress & & & & & & \\
IH & 0.510 & 0.927 & 1.13 & 0.927 & 1.02 & 0.937 \\
OL & 0.879 & 0.843 & 1.06 & 0.843 & 1.04 & 0.883 \\
OU & 0.466 & 0.891 & 0.974 & 0.891 & 1.05 & 0.911 \\
\hline
\end{tabular}

${ }^{*}$ The intercept of the regression equation was assumed to be zero.

*2 Determination coefficients for P2W are identical to those for P1W, because the responses of canopy conductance to meteorological factors for $\mathrm{P} 2 \mathrm{~W}$ are same as those for P1W.

${ }^{* 3}$ Low determination coefficients for IK were primarily caused by the small number of data with low $E$ due to rejection of data recorded on rainy days. When including data recorded on rainy days in the analysis, the determination coefficients were 0.829 , 0.829 , and 0.858 for P1W, P2W, and P3W, respectively. 